\title{
STUDY OF TURBULENT HEAT TRANSFER OF THE NANOFLUIDS IN A CYLINDRICAL CHANNEL
}

\author{
A.V. Minakov ${ }^{1,2}$, D.V. Guzei², M.I. Pryazhnikov², V.A. Zhigarev ${ }^{2}$,V.Ya. Rudyak ${ }^{1,3}$ \\ ${ }^{1}$ Kutateladze Institute of Thermophysics, SB RAS, Novosibirsk, \\ ${ }^{2}$ Siberian Federal University, Krasnoyarsk \\ ${ }^{3}$ Novosibirsk State University of Architecture and Civil Engineering \\ E-mail: tov-andrey@yandex.ru
}

\begin{abstract}
The experiment investigation of turbulent forced convection of nanofluids with $\mathrm{SiO}_{2}$ and $\mathrm{Al}_{2} \mathrm{O}_{3}$ nanoparticles was carried out. Nanoparticle concentration varied in the range from 0.5 to $2 \mathrm{vol} . \%$ in the experiments. The nanoparticle size ranged from 10 to $100 \mathrm{~nm}$. The dependence of heat transfer coefficient and pressure drop from the concentration, size, material of the nanoparticles and temperature was studied. It was shown that adding nanoparticles to the coolant significantly influences the heat transfer coefficient in the turbulent flow regime. It is shown that with increasing nanoparticles concentration, the local and average heat transfer coefficients at a fixed Reynolds number increase. Decrease in heat transfer coefficient with increasing particles concentration may take place at a fixed flow rate. It is shown that, the heat transfer coefficient of the nanofluid in turbulent regime increases with increasing nanoparticles size at a fixed flow rate, while has a certain maximum at a fixed Reynolds number. The effect of nanoparticles material on the heat transfer coefficient and pressure loss has been also demonstrated. It is found that the inlet temperature is another factor having a significant effect on turbulent heat transfer performance of nanofluids.
\end{abstract}

Keywords: nanofluids, turbulent heat transfer, forced convection, thermal conductivity, viscosity, pressure drop, nanoparticle size. 
$N u$ - is the Nusselt number;

$\alpha-$ is the average heat-transfer coefficient;

$\mathrm{G}$ - mass flow rate;

$C_{p}-$ is the specific heat of the fluid;

$S$ - is the area of the lateral surface of the channel;

$T_{\text {out }}, T_{\text {in }}$ - are fluid temperatures at the channel inlet and outlet;

$\bar{T}-$ is the average fluid temperature;

$T_{w}$ - is the arithmetic mean of the channel wall temperature, obtained by averaging of the values of six thermocouples;

$\mathrm{Pr}-$ is the Prandtl number;

$\mathrm{Re}-$ is the Reynolds number;

$\lambda$ - are fluid thermal conductivity coefficient;

$\mu$ - are fluid viscosity coefficient;

$U-$ is the superficial velocity;

$d$ - is the tube diameter;

$\mathrm{L}-$ is the test section length;

$\Delta P$ - is the measured pressure drop;

$\xi-$ is the friction factor;

$\mu_{\mathrm{n}}-$ are nanofluid viscosity coefficient;

$\mu_{\mathrm{w}}-$ are water viscosity coefficient;

$\lambda_{n}$ - are nanofluid thermal conductivity coefficient;

$\lambda_{\mathrm{w}}-$ are water thermal conductivity coefficient;

$\lambda_{\mathrm{p}}$ - are particles thermal conductivity coefficient;

$\varphi$ - volume concentration of particles.

\section{Introduction}

The enhancement of convective heat transfer and the related experimental and theoretical research become at present an independent, important and rapidly developing field of heat transfer theory. High heat flux removal is a major consideration in the design of many machines, equipment and technologies, and can be accomplished using various kinds of heat transfer equipment. The urgency of this problem is determined by driving to enhance the performance of heat exchange devices, reduce energy costs and achieve maximum compactness with minimum material consumption. One of the solutions to the problem of heat transfer performance enhancement could be the use of so called nanofluids, which are fluids containing nanoparticles of various composition. The first experiments have shown that even very small additions of nanoparticles to the fluid (a fraction of volume concentration) may lead to increase in thermal conductivity and heat transfer of the nanofluid by tens of percent, whereas the critical heat flux may be increased several times ([1-5]). Over the last two decades, a great number of works have been emerged in this area. Most of them were focused on the study of thermal conductivity and 
viscosity of nanofluids. Actually, the study of heat transfer was performed in a relatively few research works, and the results presented are extremely controversial (see the review [5]). Most works reveal an increase in heat transfer when using nanoparticles. The increase in heat transfer coefficient in nanofluids as compared to base fluids can range from a few percent to $350 \%$ for carbon nanotubes. However, there are publications showing the deterioration of heat transfer when adding nanoparticles. Most of these works are dealt with the study of convection of nanofluids in laminar flow regime [6-9]. Turbulent convection is explored to a substantially lesser degree.

The first work, in which the turbulent heat transfer of nanofluids was studied, is apparently the work of Pak and Cho [10]. They experimentally studied the turbulent heat transfer in waterbased nanofluids, containing $\mathrm{Al}_{2} \mathrm{O}_{3}$ and $\mathrm{TiO}_{2}$ nanoparticles, and flowing in a horizontal circular pipe with a constant wall heat flux. The results have shown that the Nusselt number in nanofluids increases with increasing both bulk concentration of the particles and the Reynolds number. However, in the same paper [10] it has been revealed also that at high concentrations of nanoparticles the heat transfer coefficient may be lower than that in pure water (by $12 \%$ in a nanofluid with particles concentration of $3 \%$ ).

Convective heat transfer in turbulent flow regime of nanofluids containing copper nanoparticles was experimentally investigated in the subsequent work [11]. The experimental results have shown that adding nanoparticles to the base fluid significantly improved the heat transfer efficiency of base fluid (by $60 \%$ in a nanofluid with particles concentration of $2 \%$ ), while the friction factor remained almost the same as for water.

In [12] the efficiency of heat transfer in water-based nanofluids containing titanium oxide nanoparticles was investigated in laminar and turbulent flow regimes in vertical tube under constant wall heat flux boundary condition. The results have shown that the heat transfer coefficient definitely increases with increase of nanoparticles concentration in both laminar and turbulent regimes at a fixed Reynolds number. The maximum intensification of heat transfer coefficient, recorded in the experiment, was $40 \%$ for $1.1 \%$ nanofluid. In this case, the pressure drop in nanofluids, when flowing in the channel, was very close to that in pure fluid. In addition, the authors investigated the effect of particles size, though no effect of size on the heat transfer coefficient was detected, possibly, because the particles were large enough $(95-210 \mathrm{~nm})$.

Duangthongsuk and Wongwises [13] experimentally studied turbulent heat transfer and pressure drop in water-based nanofluids with $\mathrm{TiO}_{2}$ particles. And again the results were extremely controversial. They revealed a $32 \%$ enhancement in thermal performance at particles concentration of $1 \%$, and $14 \%$ reduction in the heat transfer coefficient at particles concentration of $2 \%$ as compared with the pure fluid. 
Fotukian and Nasr Esfahany [14] studied turbulent convective heat transfer in nanofluids with a very low concentration of $\mathrm{Al}_{2} \mathrm{O}_{3}$ nanoparticles in water flowing in a circular pipe. They recorded a clear increase in heat transfer coefficient and pressure drop with increasing concentration of particles. The maximum increase of heat transfer coefficient equal to $48 \%$ was reached at negligibly small volume concentration of the nanoparticles $(0.054 \%)$. In a subsequent paper [15] the same authors studied turbulent heat transfer of water-based nanofluids containing $\mathrm{CuO}$ nanoparticles in a circular pipe. They achieved a $25 \%$ increase in the heat transfer coefficient and a $20 \%$ increase in pressure drop at a concentration of nanoparticles equal to $0.24 \%$, as compared to pure water. Besides, they revealed that the heat transfer coefficient was almost independent of the concentration of nanoparticles within the observed range of volume percent change from 0.039 to 0.24 .

Nguyen et al. [16] experimentally investigated the heat transfer coefficient in the liquid cooling system of microprocessors using water-based nanofluid containing nanoparticles of $\mathrm{Al}_{2} \mathrm{O}_{3}$ at a turbulent flow regime. They found that nanofluid significantly increases the heat transfer coefficient as compared to base fluid (by $40 \%$ at particles concentration of $6.8 \%$ ). Besides, they investigated the effect of particle size on turbulent heat transfer. The authors revealed that the nanofluid containing particles of $36 \mathrm{~nm}$ in size provided a higher heat transfer coefficient as compared to the nanofluid with particles size of $47 \mathrm{~nm}$.

Extensive experimental studies of turbulent convective heat transfer in the annular channel for several water-based nanofluids containing $\mathrm{Al}_{2} \mathrm{O}_{3}, \mathrm{SiO}_{2}$, and $\mathrm{MgO}$ particles was carried out in [17]. The authors revealed considerable increase in heat transfer coefficient with increasing particles concentration (by $46 \%$ in a $4 \%$ nanofluid containing particles of $\mathrm{SiO}_{2}$ ), and argued that in general the heat transfer coefficient increased with decreasing particle size. However, the authors used in their study particles of substantially different shapes (cylinders with sizes of 28$110 \mathrm{~nm}$ and spheres with diameter of $6.5 \mathrm{~nm}$ ). Thus, such a comparison seems incorrect.

Heat transfer in nanofluid based on the mixture of water and ethylene glycol with particles of silicon carbide was experimentally investigated in [18]. The particle size ranged from 16 to $90 \mathrm{~nm}$. It was shown that with increasing particle size at other conditions being equal the heat transfer coefficient increased significantly.

In addition, it should be noted that there are a huge number of computational studies of turbulent heat transfer in nanofluids. Though, in our view, these studies are not self-containing because they require experimental data on transport coefficients. Therefore, analyzing these works, which are characterized by the inconsistency of the experimental data, apparently does not make much sense. 
Thus, the analysis of the literature shows that in the available works there is neither quantitative nor qualitative consensus in terms of turbulent heat transfer performance of nanofluids. In the meantime, almost all scientists note that the effect of nanoparticles on the heat transfer in the turbulent flow regime is much more complicated than that in laminar flow regime. This circumstance requires additional systematic experimental study of turbulent heat transfer of nanofluids.

\section{Description of the experimental setup}

The diagram of the installation to study the heat transfer coefficient is shown in Fig 1. The installation is a closed loop with a circulating coolant [7-9]. The working fluid is pumped through the heated test section to the heat exchanger, where heat is removed by the thermostat. The flow rate of the working fluid in the loop is controlled by controlling the pump power by means of laboratory transformer. Power input to the pump is measured through Omix meter.

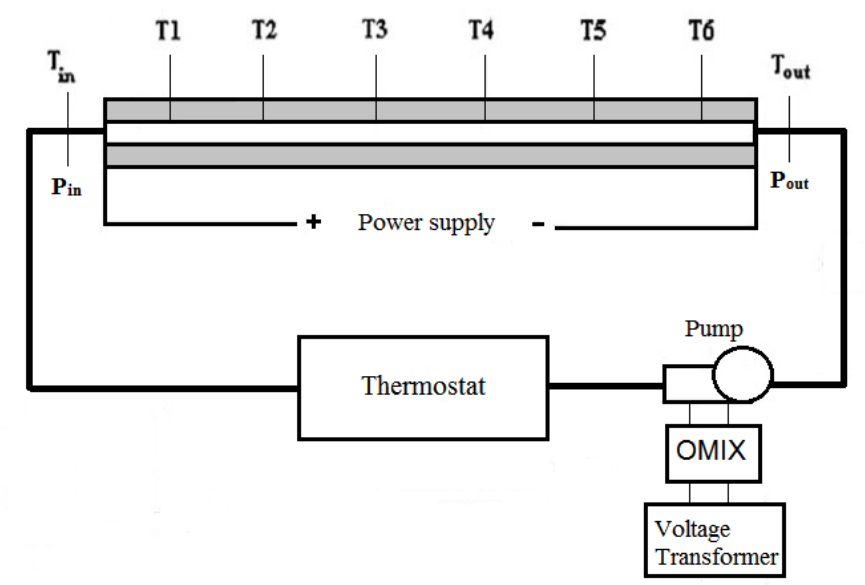

Fig.1. A schematic diagram of the measuring system.

The heated test section is a stainless steel tube $6 \mathrm{~mm}$ in diameter, $1 \mathrm{~m}$ long with wall thickness of $0.5 \mathrm{~mm}$. The tube was heated by supplying electric current directly to its wall. This heating technique allows obtaining a constant wall heat flux boundary condition. In addition, this heating technique is universal and easily applicable to tubes of any cross section. The tube is insulated by multi-layer insulation. The heating power is controlled by a transformer. Six chromel-copel thermocouples fixed on the tube wall at the equal distance from each other were used to measure the local temperature of the tube. Temperature measurements were carried out by TPM-200 meters. In addition, the temperatures at the inlet and outlet of the heated test section were measured using thermocouples. At that, the thermocouple designed to measure the fluid temperature at the outlet of the loop was located at a considerable distance from the end of the heated test section to ensure uniformity of the fluid temperature in the metering point. To determine the temperature of the liquid at the outlet the 
liquid must be very good to mix. To do this, at the exit of the heated channel equipped with a special mixer. The mixer is a cylindrical chamber with a diameter $3 \mathrm{~cm}$ and $5 \mathrm{~cm}$ in length, filled with polypropylene rings (diameter of $5 \mathrm{~mm}$ and a length of $7 \mathrm{~mm}$ ). The mixer and loop section between the heater and the fluid temperature metering point was also insulated.

In all experiments, electric power supplied heater was measured. This electric power compared with the heat capacity transferred to liquid. The installation was well heat insulated. Therefore, the difference between the thermal and electrical capacities not exceed 3-5\%.

The pressure drop measurements were carried out using a differential manometer OWEN PD200. The designed experimental setup was tested based on known empirical data for heat transfer of pure water. The water flow rate ranged from 0.65 to $21 / \mathrm{min}$ that corresponds to the range of Reynolds number from 2300 to 8000.

\section{The testing of the experimental setup}

Figure 2 shows the comparison of the experimental data on the average Nusselt number depending on the Reynolds number with the known empirical correlation [19]:

$$
N u=0.021 \cdot \operatorname{Re}^{0.8} \operatorname{Pr}^{0.43},
$$

where $N u=\alpha d / \lambda-$ is the Nusselt number, $\alpha=G C_{P}\left(T_{\text {out }}-T_{\text {in }}\right) S^{-1}\left(T_{w}-\bar{T}\right)^{-1}-$ is the average heat-transfer coefficient; $G$ - mass flow rate, $C_{p}$ - is the specific heat of the fluid; $S$-is the area of the lateral surface of the channel; $T_{\text {out }}, T_{\text {in }}$ - are fluid temperatures at the channel inlet and outlet; $\bar{T}=\left(T_{\text {in }}+T_{\text {out }}\right) / 2$ - is the average fluid temperature; $T_{w}-$ is the arithmetic mean of the channel wall temperature, obtained by averaging of the values of six thermocouples; $\operatorname{Pr}-$ is the Prandtl number; $\operatorname{Re}=\rho U d / \mu-$ is the Reynolds number; $\lambda$ and $\mu-$ are fluid thermal conductivity and viscosity coefficients, respectively; $U$ - is the superficial velocity; and $d$ - is the tube diameter. This values calculated at average temperature $\bar{T}=\left(T_{\text {in }}+T_{\text {out }}\right) / 2$.

As is obvious from the plots presented in Fig. 2, experimental data obtained in the turbulent flow regime, are in good agreement with the empirical correlation [19]. The discrepancies do not exceed $5 \%$ that is comparable to the accuracy of the correlation. 


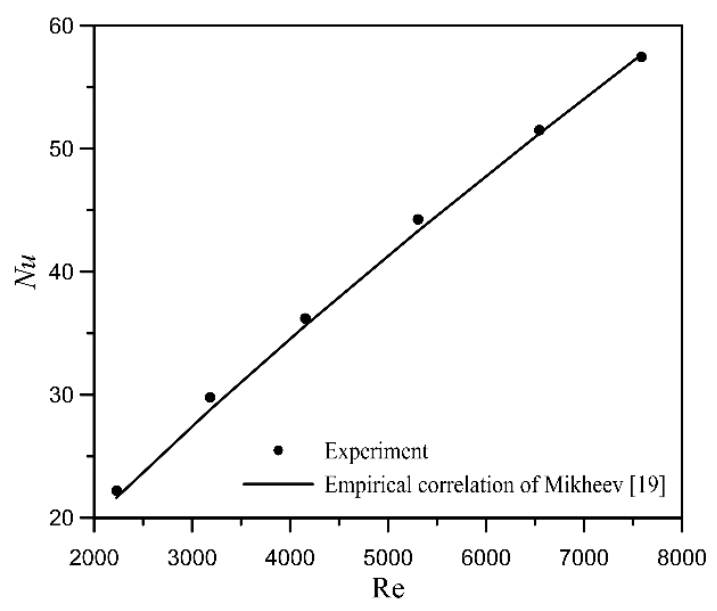

(a)

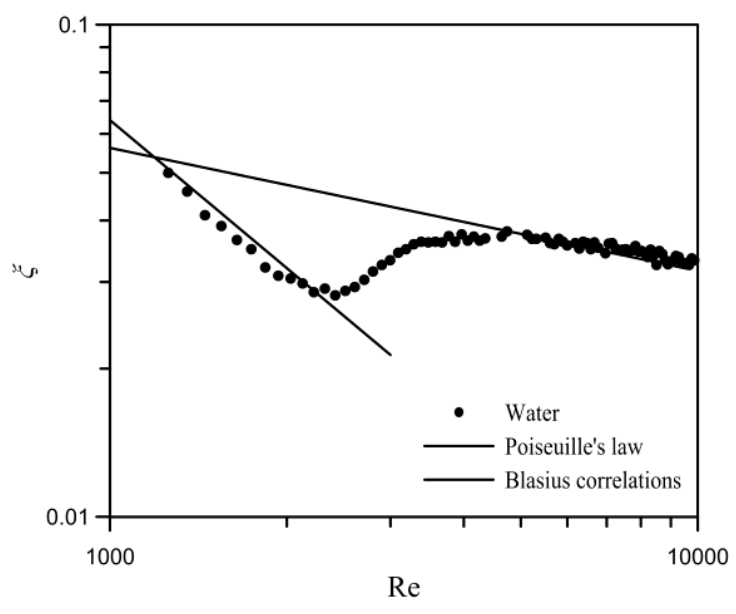

(b)

Fig.2. Heat transfer coefficient (a) and friction factor (b) for pure water versus Reynolds number.

In addition to the heat transfer of pure water, pressure drop was measured as well. Figure $2 \mathrm{~b}$ shows the measured correlation between friction factor and Reynolds number for pure water. The friction factor was calculated by known formula:

$$
\xi=\frac{2 d \cdot \Delta P}{\rho U^{2} L} .
$$

where $U$ - is the superficial velocity; $d$ - is the diameter; $\mathrm{L}$ - is the test section length; and $\Delta P$ - is the measured pressure drop.

For comparison, the chart shows also calculations by Poiseuille's theoretical relationship $\xi=\frac{64}{R e}$ for laminar flow and Blasius correlation $\xi=0.316 R e^{-0.25}$ for turbulent flow. It is obvious that within the range of Reynolds numbers from 2300 to 3000 we observe flow transition from laminar to turbulent regime. The measured pressure drop values are consistent with the theoretical values with an accuracy of $5 \%$.

\section{Experimental results}

Next, an experimental study of turbulent heat transfer of nanofluids in a cylindrical channel at a constant wall heat flux was carried out. Powders of silicon and aluminum oxides were used as nanoparticles, while distilled water was employed as the base fluid. The size of the nanoparticles ranged from 10 to $100 \mathrm{~nm}$. Measurement of nanoparticles distribution over size directly in a fluid was carried out by means of the DC24000 CPS Disk Centrifuge, as well as monitored by electron microscopy (Fig. 3). Bulk concentration of nanoparticles was varied within the range from 0 to 2 volume percent. Nanopowders were purchased from JSC "Plazmoterm", Moscow. The resulting suspensions were subjected to the half-hour ultrasonic treatment in a "Sapphire" bath. The nanofluids were free of surfactants. The viscosity of the nanofluids was measured using a rotational viscometer DV2T. Viscosity measurements were 
carried out within the range of shear velocity from 10 to $2001 / \mathrm{s}$ at a temperature of $25{ }^{0} \mathrm{C}$. Before the measurements, the viscometer was calibrated with distilled water and ethylene glycol. The results obtained were in a good agreement with the reference data.

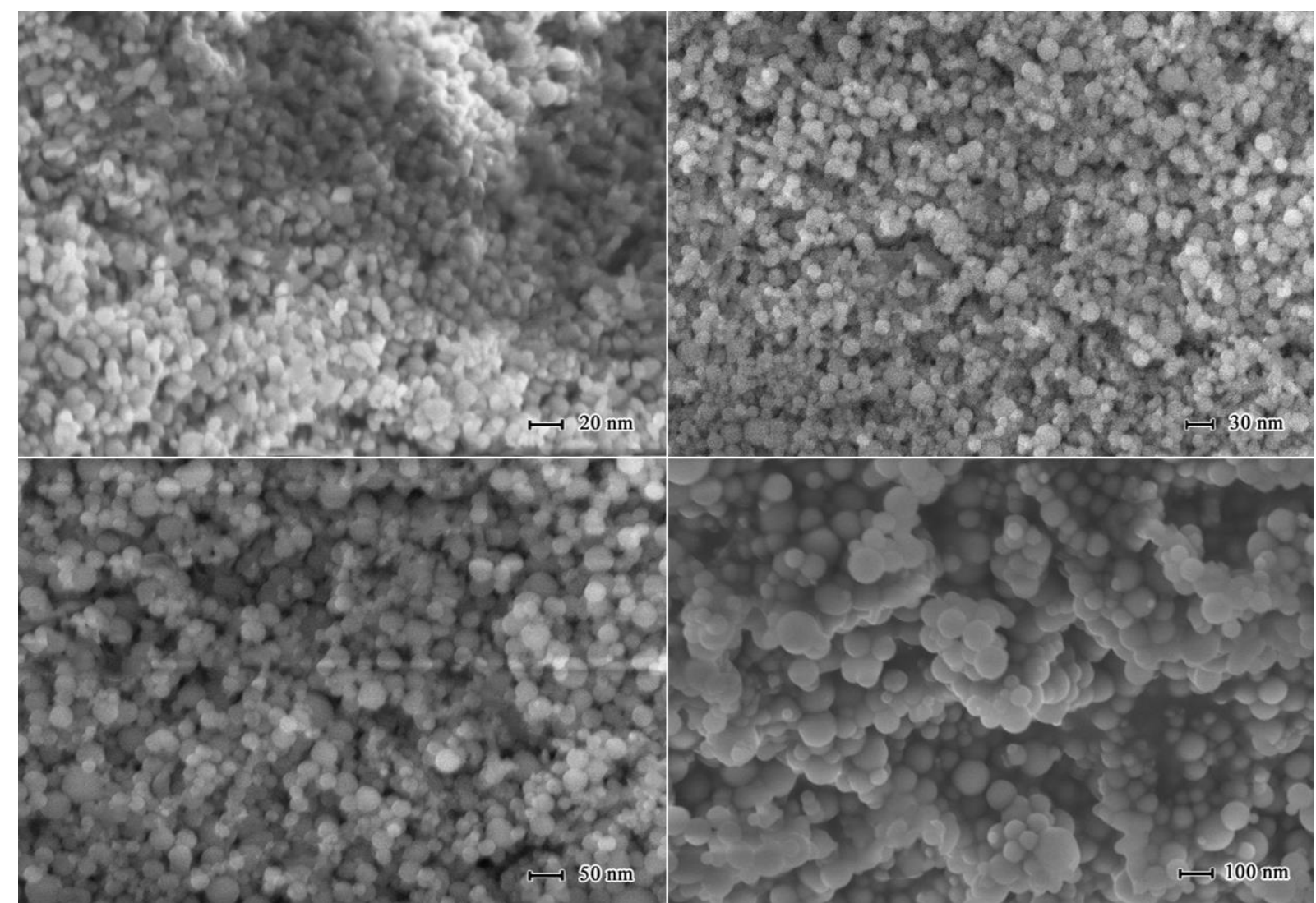

Fig.3. Electron microscopy.

The coefficient of thermal conductivity of nanofluids was measured using a non-stationary hot wire method. The detailed description of the installation and its testing is given in [20].

The conducted experiments allowed measuring the coefficients of viscosity and thermal conductivity of nanofluids, the average and local values of wall heat transfer coefficient, and the pressure gradient at the inlet and outlet of the channel. The all experiments except the experiments in the Section 3.4 were carried out at inlet fluid temperature $25^{\circ} \mathrm{C}$.

\subsection{The effect of particles concentration}

First, we investigated the effect of nanoparticles concentration on the average heat transfer coefficient. This study was carried out for water-based nanofluid containing silica particles with an average size of $25 \mathrm{~nm}$. The obtained experimental data for different concentrations of nanoparticles are shown in Fig. 4. As is obvious, the heat transfer coefficient at a fixed flow velocity depends on the nanoparticles concentration. At a fixed flow velocity, the heat transfer coefficient for a $2 \%$ nanofluid is about $10 \%$ lower than that for pure water. 
With the decrease of nanoparticles concentration, the heat transfer coefficient monotonically tends to the level corresponding to that of pure water. For the nanofluid with $0.25 \%$ concentration, the heat transfer coefficient exceeds the values for pure water.

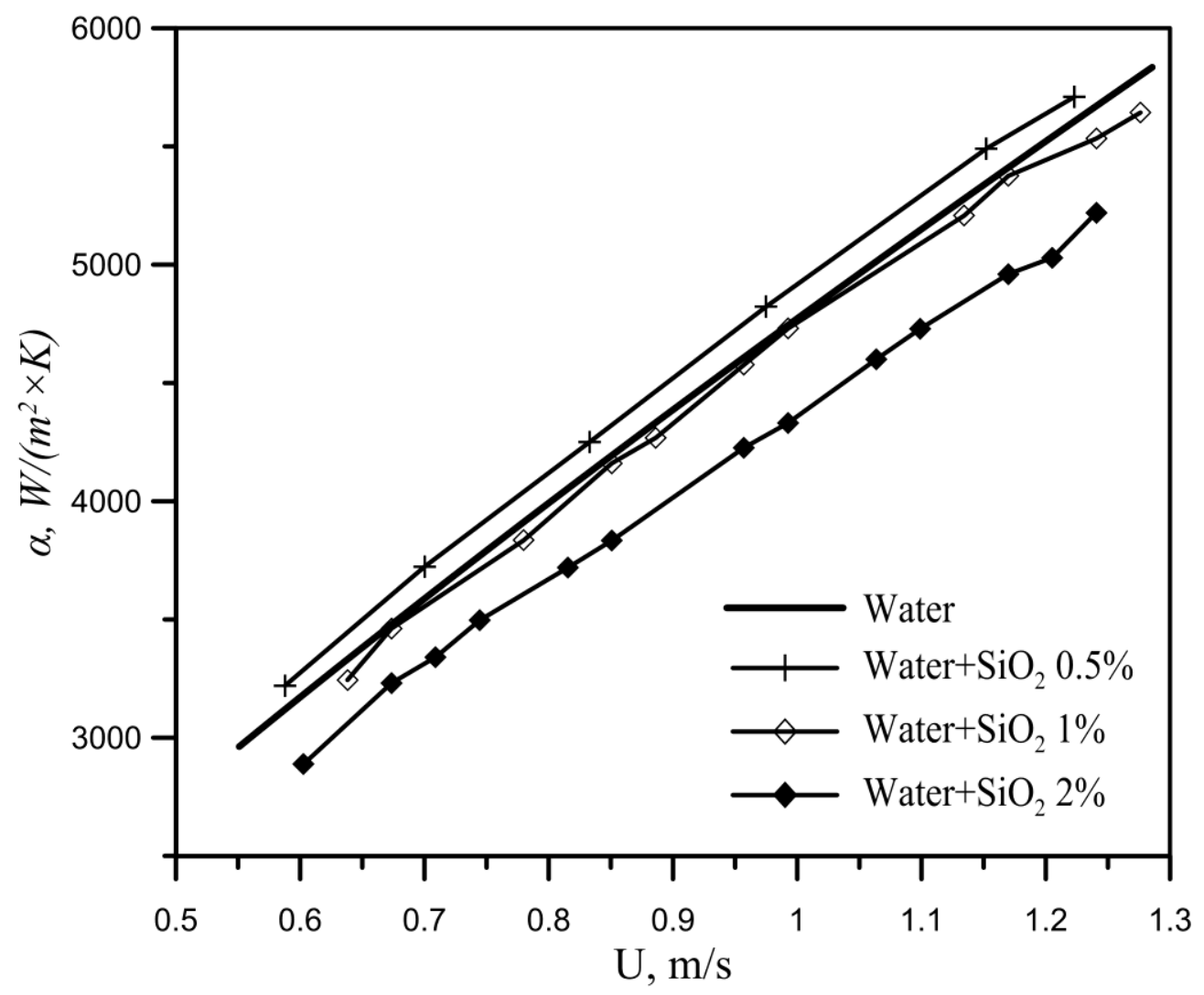

Fig. 4. Average heat-transfer coefficient versus flow velocity for different concentrations of $\mathrm{SiO}_{2}$ nanoparticles with a size of $25 \mathrm{~nm}$.

Most works on the study of forced convection in nanofluids analyze heat transfer performance depending on the Reynolds number. This dependence is shown in Fig. 5. It is obvious that the average heat transfer coefficient significantly depends on the concentration of nanoparticles. At a fixed Reynolds number, with increasing nanoparticles concentration, heat transfer coefficient increases. Heat transfer coefficient for the nanofluid with nanoparticles concentration of $2 \%$ is higher than that in pure water by more than $15 \%$. With the decrease in nanoparticles concentration, the heat transfer coefficients monotonically tend to the values corresponding to pure water. 


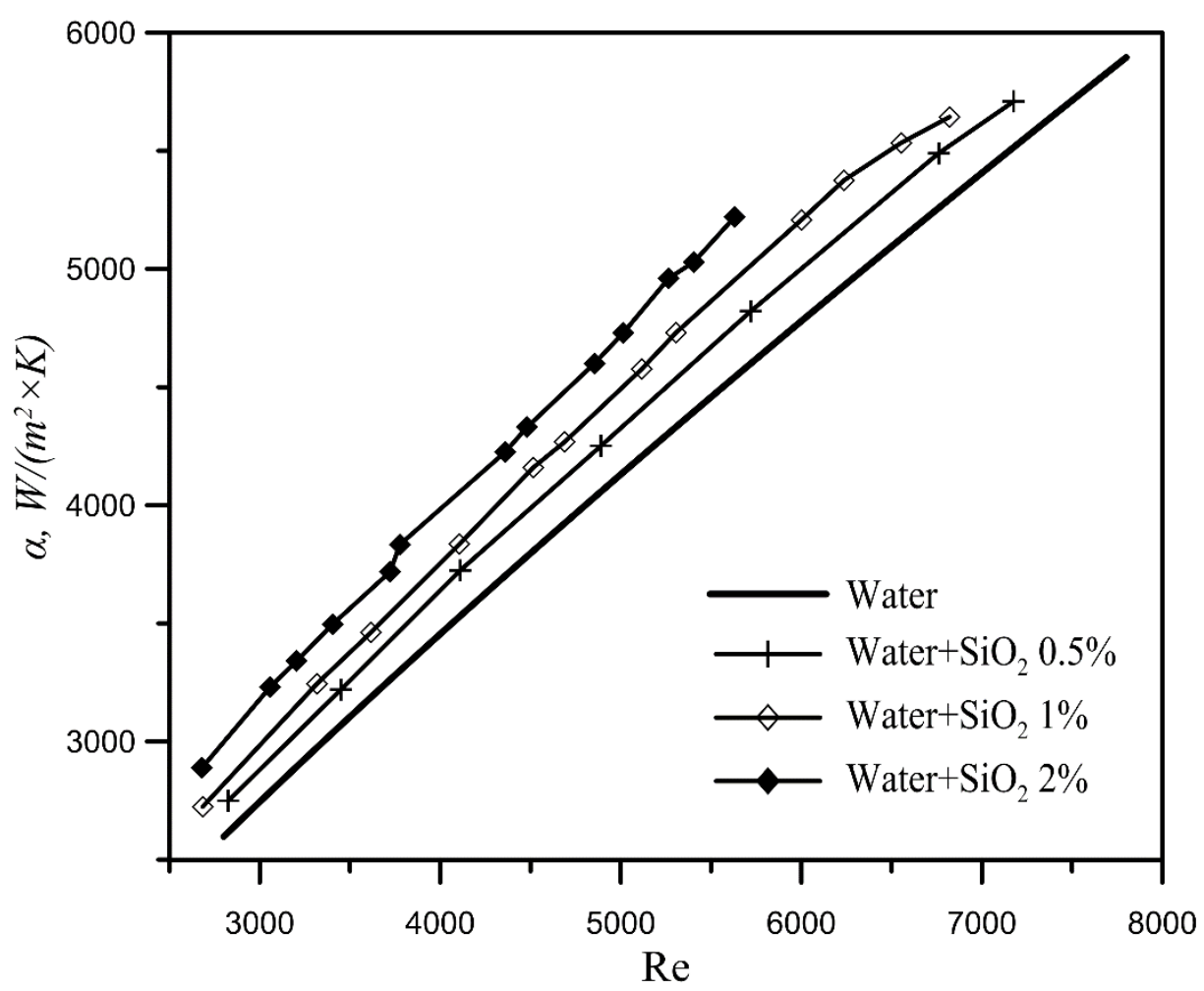

Fig. 5. Average heat transfer coefficient versus Reynolds number for different concentrations of $\mathrm{SiO}_{2}$ nanoparticles with a size of $25 \mathrm{~nm}$.

It is of interest to analyze difference of the average heat transfer coefficient at a fixed fluid velocity (or flow rate) see Fig 4 and of the average heat transfer coefficient at a fixed Reynolds (Fig. 5). It is seen that the observed heat transfer enhancement at a fixed Reynolds number considerably exceeds the heat transfer enhancement at a fixed flow rate (of fluid velocity).

This seemingly unusual behavior is due to the fact that nanoparticles affect not only thermal conductivity, but also the viscosity of nanofluids. The dependence of viscosity coefficients of a given nanofluid on particles concentration is shown in Fig.6a and Table 1, where black line corresponds to calculation by Einstein formula [21]

$$
\mu_{n} / \mu_{w}=1+\frac{5}{2} \varphi
$$

which is appropriate for Brownian particles. As is obvious from Fig.6a, the viscosity of nanofluid is significantly higher than that calculated by the classical formula of Einstein. This behavior is typical of the nanofluids, in contrast to the classical colloidal solutions.

Though, in this case thermal conductivity coefficient of nanofluid is well described by the Maxwell dependence [22]

$$
\frac{\lambda}{\lambda_{f}}=\frac{\lambda_{p}+2 \lambda_{f}+2 \varphi\left(\lambda_{p}-\lambda_{f}\right)}{\lambda_{p}+2 \lambda_{f}-\varphi\left(\lambda_{p}-\lambda_{f}\right)} \quad \text { (see Fig. } 6 \mathrm{~b} \text { and Table 1). }
$$




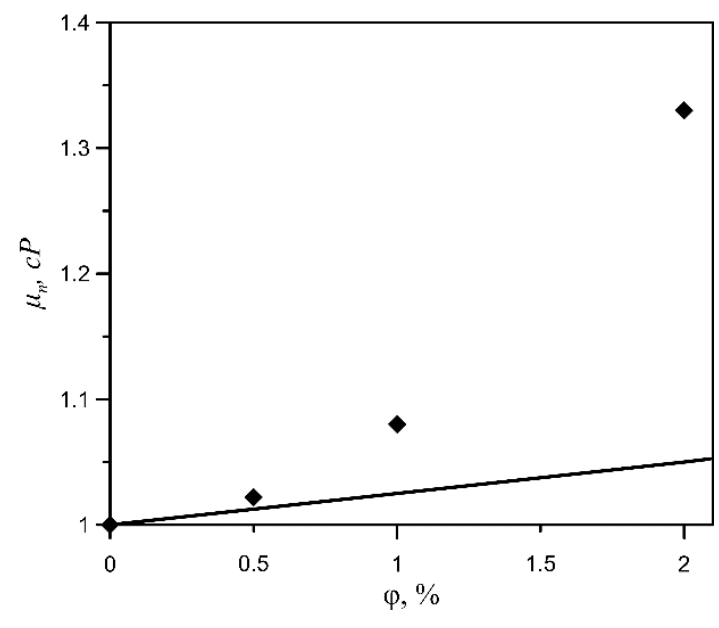

(a)

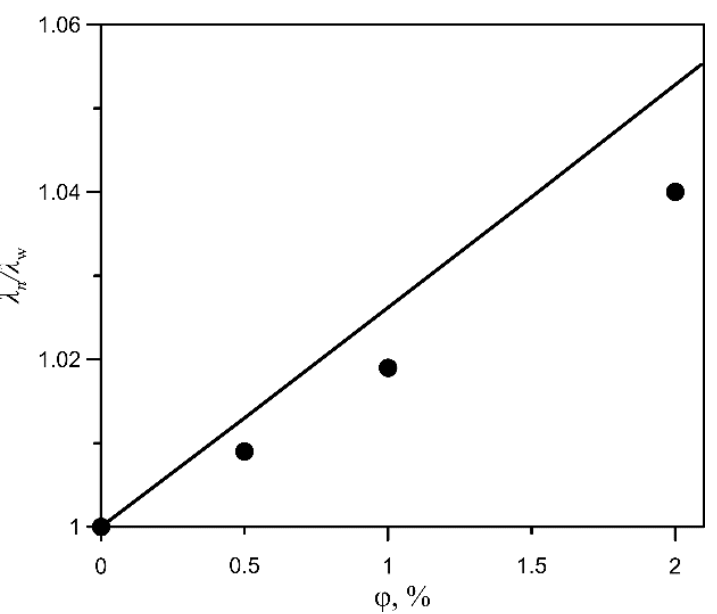

(b)

Fig.6. Viscosity (a) and thermal conductivity (b) of nanofluid versus concentration of $\mathrm{SiO}_{2}$ nanoparticles with a size of $25 \mathrm{~nm}$.

Table 1. Viscosity and thermal conductivity of nanofluid versus concentration of $\mathrm{SiO}_{2}$ nanoparticles with a size of $25 \mathrm{~nm}$.

\begin{tabular}{|c|c|c|}
\hline$\varphi, \%$ & $\mu_{\mathrm{n}}, \mathrm{cP}$ & $\lambda_{\mathrm{n}} / \lambda_{\mathrm{w}}$ \\
\hline 0.5 & 1.022 & 1.009 \\
\hline 1 & 1.08 & 1.019 \\
\hline 2 & 1.33 & 1.04 \\
\hline
\end{tabular}

For a qualitative understanding of the relationship between the heat transfer coefficient and the nanoparticles concentration we refer to the well-known Mikheev's formula $N u=0.021 \cdot \operatorname{Re}^{0.8} \operatorname{Pr}^{0.43}$, which describes the heat transfer in the developed turbulent flow. It follows from this formula that the heat transfer coefficient depends on the viscosity in markedly different ways subject to a fixed Reynolds number or a fixed fluid flow rate. It is not difficult to show that $\alpha \sim \mu^{0.43} \cdot \lambda^{0.57}$ at $\operatorname{Re}=$ const and $\alpha \sim \mu^{-0.37} \cdot \lambda^{0.57}$ at $G=$ const. Thus in the first case $(\mathrm{Re}=\mathrm{const})$, when using nanofluid as a coolant, we will always get an increase in heat transfer coefficient and, moreover, the greater the nanofluid viscosity, the greater heat transfer coefficient even if the thermal conductivity is almost not changed. And since with increasing particle concentration, the viscosity of nanofluid increases generally significantly stronger than the thermal conductivity, than the increase in heat transfer at a fixed Reynolds number revealed in most studies can be explained by the increase in viscosity. From a practical viewpoint, the most challenging is the case, where coolant flow rate or velocity is fixed. Here the situation is much more complicated. In this case, if the increase in thermal conductivity of the coolant due to the 
concentration of nanoparticles is significantly less than the increase in its viscosity, this may result in deterioration of heat transfer performance. This is shown in Fig. 4. The analysis of the works of other authors also confirmed this fact. The papers, where the heat transfer performance was analyzed at a fixed Reynolds number, usually indicate increase in heat transfer coefficients and, moreover, this increase is quite significant, whereas in the papers, where analysis was conducted at a fixed flow rate, heat transfer coefficients either decreased or increased just slightly.

For nanofluids, the key difference between the turbulent and laminar heat transfer consists in the dependence of the heat transfer coefficient on the viscosity under the steady state conditions. In the case of steady laminar flow regime the heat transfer coefficient is proportional to the thermal conductivity of the fluid and does not depend on viscosity. Since thermal conductivity of the fluid due to the presence of the nanoparticles always increases, in the laminar flow we have a clear enhancement of heat transfer regardless of how the viscosity increased [7]. In the turbulent flow, the situation is much more complicated, because heat transfer coefficient depends nonlinearly not only on the thermal conductivity of the fluid, but also on its viscosity. Here, if the increase in thermal conductivity of the fluid due to the nanoparticles is significantly less than the increase in its viscosity, this may lead to deteriorated heat transfer that was evidenced in the present experiments.

The behavior of the Nusselt number is also interesting. The Nusselt number indicate the law of heat transfer with the influence of thermal properties of nanofluids. The dependence of the average Nusselt number $N u=\alpha \cdot d / \lambda$ from versus flow velocity and Reynolds number is shown in Fig. 7. At a fixed flow velocity, the average Nusselt number for a $2 \%$ nanofluid is about $12 \%$ lower than that for pure water. With the decrease of nanoparticles concentration, the average Nusselt number monotonically tends to the level corresponding to that of pure water. For the nanofluid with $0.25 \%$ concentration, the average Nusselt number exceeds the values for pure water. At a fixed Reynolds number, the average Nusselt number for a $2 \%$ nanofluid is higher than that in pure water by more than $13 \%$. 


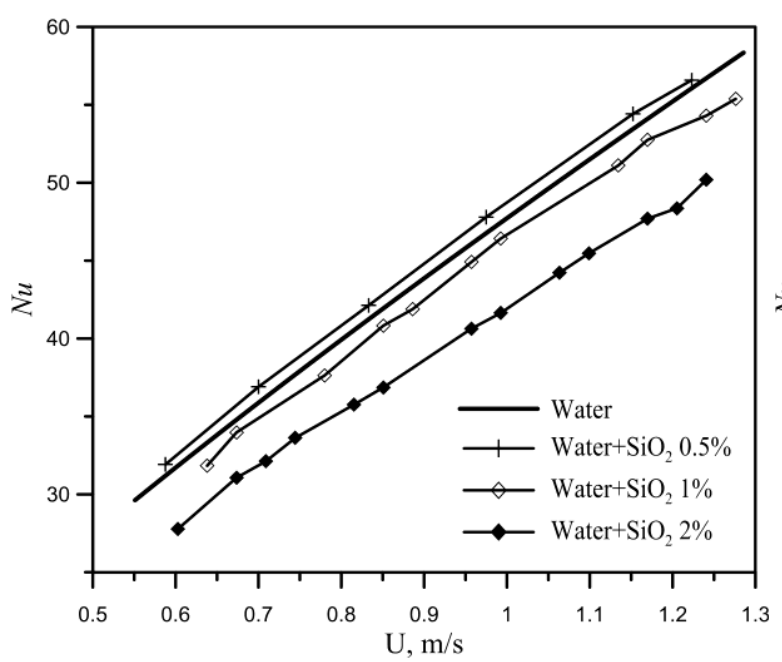

(a)

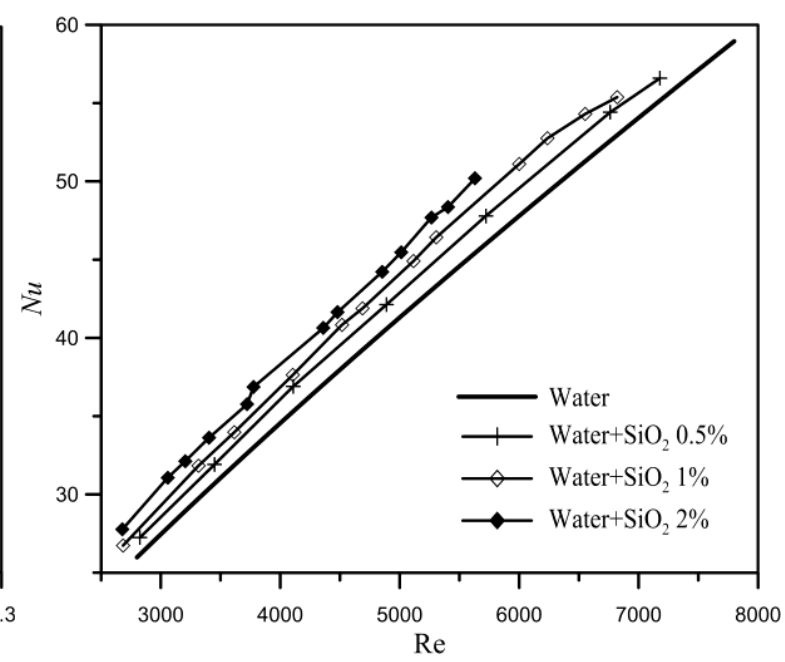

(b)

Fig. 7. Average Nusselt number versus flow velocity (a) and Reynolds number (b) for different concentrations of $\mathrm{SiO}_{2}$ nanoparticles with a size of $25 \mathrm{~nm}$.

Thus, it was shown that heat transfer enhancement due to the use of nanofluids in the turbulent regime is a non-trivial problem. Beneficial effect in terms of heat transfer enhancement depends on the ratio between viscosity and thermal conductivity of the nanofluid, and thus, on particles material and size. This apparently explains such a wide variations and inconsistency of experimental data on turbulent heat transfer presented by various authors.

Besides, the effect of nanoparticles concentration on the pressure drop in the channel is of great interest from practical viewpoint. Figures 8-9 present measured data on pressure drop in the test section for the nanofluid containing silicon oxide (with a particle size of $25 \mathrm{~nm}$ ) depending on the flow rate and Reynolds number. As is obvious, with increasing nanoparticles concentration, the pressure drop in the channel increases. This is clear, since nanofluid has a higher viscosity. Measured data on the nanofluid viscosity depending on particles concentration is shown in Fig. 6a. As can be seen, the viscosity of a $2 \%$ nanofluid is approximately by $40 \%$ higher than the viscosity of pure water. Besides, we can see that the increase in pressure as well as in heat transfer coefficient depends on the criterion, which underlies the comparative analysis. Thus, for example, at a fixed Reynolds number (Fig.8.) a $2 \%$ concentration of the nanoparticles increase pressure drop by $75 \%$, while at a fixed flow rate (Fig. 9) - just by 6\%. A qualitative explanation of this fact can be found if we analyze the well-known Blasius formula for turbulent friction factor $\xi=0.316 R e^{-0.25}$. From this formula it follows that the pressure drop in the channel $\Delta P \approx \frac{\mu^{2}}{\rho}$ at $\operatorname{Re}=$ const and $\Delta P \approx \mu^{0.25} \cdot \rho^{0.75}$ at $G=$ const. Thus, at a fixed Reynolds number the pressure drop is proportional to the square of the viscosity, and therefore increases very significantly. At a fixed flow rate the pressure drop is proportional to viscosity to the power 
of $1 / 4$, and therefore increases slightly with increasing nanoparticles concentration. Exactly the second case is important from practical viewpoint. Therefore, concerns, expressed in many studies that nanofluids significantly increase the pressure loss on pumping are in fact unjustified.

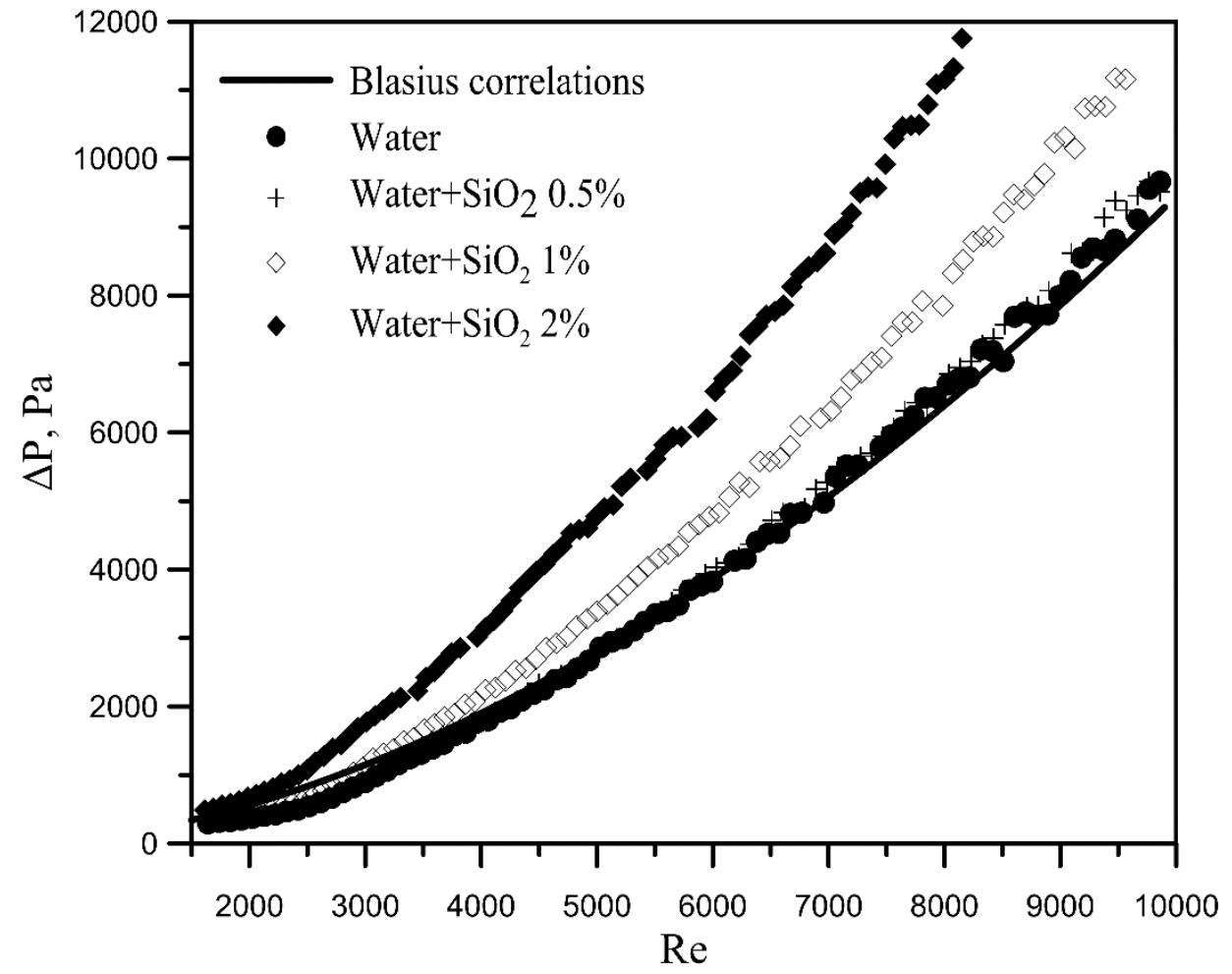

Fig.8. Pressure drop versus Reynolds number for various concentrations of $\mathrm{SiO}_{2}$ nanoparticles with a size of $25 \mathrm{~nm}$.

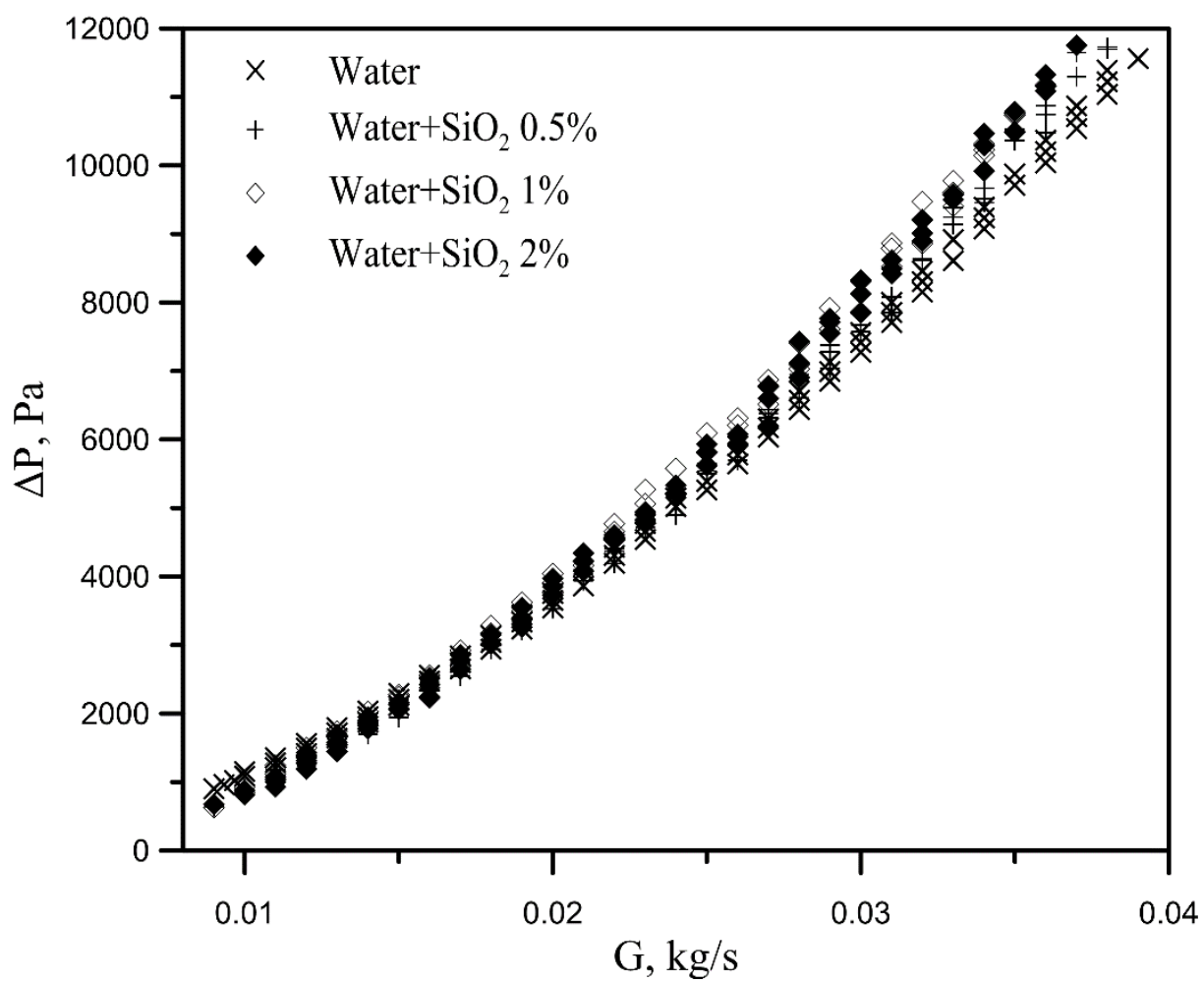

Fig.9. Pressure drop versus flow rate for various concentrations of $\mathrm{SiO}_{2}$ nanoparticles with a size of $25 \mathrm{~nm}$. 


\subsection{The effect of particle size}

Presently, the influence of particle size on the transfer coefficients of nanofluids has been well-established $[23,24]$. Thus, we should expect the effect of particle size on the heat transfer as well. Further we investigated the effect of nanoparticles diameter on the heat transfer characteristics in turbulent regime of nanofluids containing silica particles. The particles diameter ranged from 10 to $100 \mathrm{~nm}$, all other experimental conditions were similar. Figure 10 presents the dependence of the average heat-transfer coefficient on flow rate of the $2 \%$ nanofluid with particles of different size. As is obvious, at a fixed fluid flow rate the heat transfer coefficient definitely increases with increasing particle size. Again this is due to the performance of transport coefficients (see Fig.11 and Table 2). We see that in this case the viscosity of nanofluid decreases with increasing particle size, while the thermal conductivity, on the contrary, increases. It should be noted that currently in the literature there is no consensus regarding the dependence of transfer coefficients of nanofluids on the particle size. The available data are rather contradictory. This is especially true for the thermal conductivity of nanofluid. Many works $[18,25-26]$ indicate that the thermal conductivity coefficient increases with increasing particle size. Though, the fact that the viscosity decreases with increasing particles size is ascertained more reliably [23, 24]. Recall that the average heat transfer coefficient in the turbulent regime at a fixed fluid flow rate is proportional to the complex of $\mu^{-0.37} \lambda^{0.57}$. With the increase in particle size, thermal conductivity of nanofluids increases, whereas the viscosity, on the contrary, decreases and, as a consequence, heat transfer unambiguously enhances. This is shown in Fig. 10.

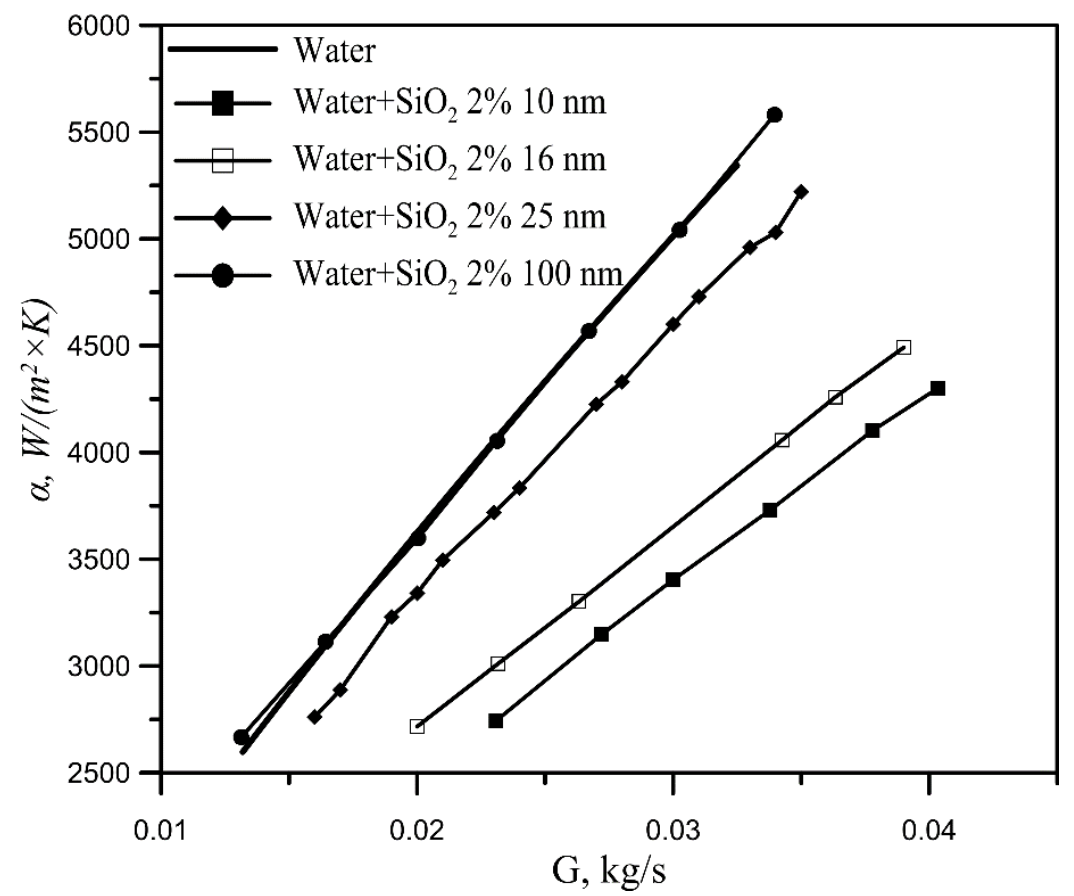

Fig. 10. Heat transfer coefficient versus flow rate for various sizes of $\mathrm{SiO}_{2}$ nanoparticles at a bulk concentration of $2 \%$. 


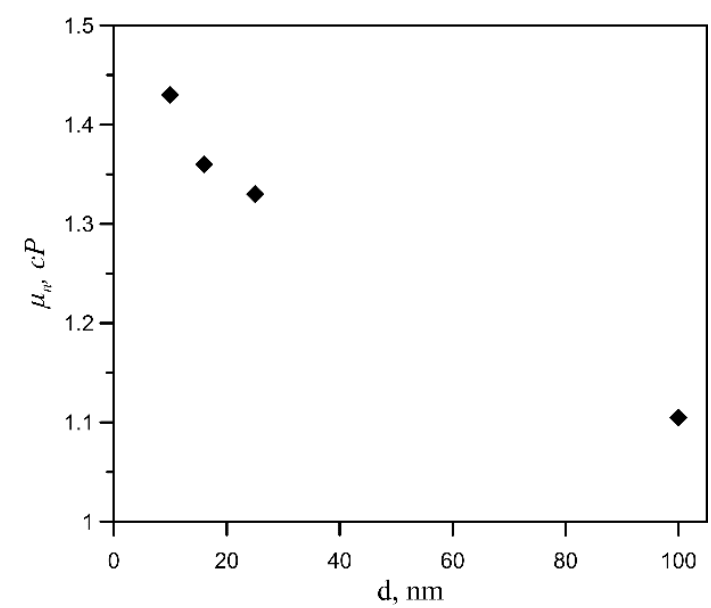

(a)

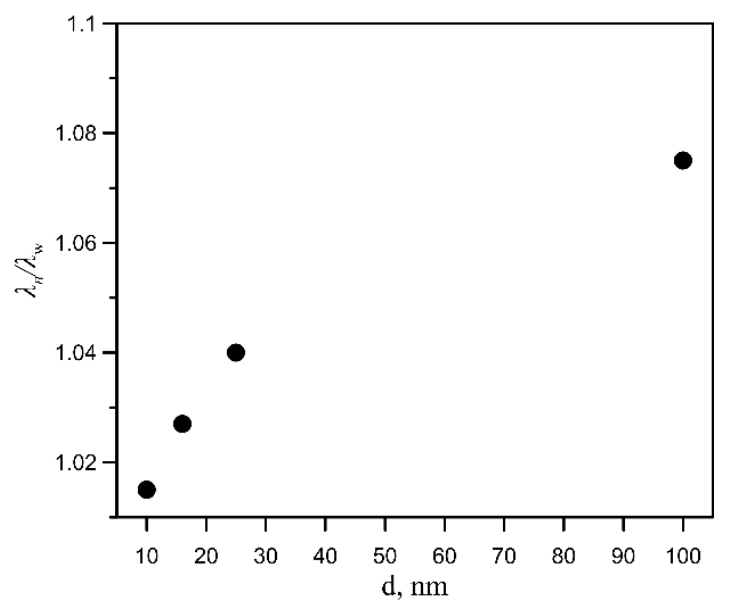

(b)

Fig.11. Viscosity (a) and thermal conductivity (b) of nanofluids versus $\mathrm{SiO}_{2}$ nanoparticles sizes at a bulk concentration of $2 \%$.

Table 2. Viscosity and thermal conductivity of nanofluids versus $\mathrm{SiO}_{2}$ nanoparticles sizes at a bulk concentration of $2 \%$.

\begin{tabular}{|c|c|c|}
\hline $\mathrm{d}, \mathrm{nm}$ & $\mu_{\mathrm{n}}, \mathrm{cP}$ & $\lambda_{\mathrm{n}} / \lambda_{\mathrm{w}}$ \\
\hline 10 & 1.43 & 1.015 \\
\hline 16 & 1.36 & 1.04 \\
\hline 25 & 1.33 & 1.027 \\
\hline 100 & 1.11 & 1.075 \\
\hline
\end{tabular}

If we look at the correlation between the heat transfer coefficient and Reynolds number (Fig.12), we find that at a fixed Reynolds number the heat transfer coefficient has a maximum at particle size of $25 \mathrm{~nm}$. The reason for this non-monotonic behavior again lies in the effect of nanoparticle size on the transfer coefficients of nanofluids. According to Mikheev's formula, at a fixed Reynolds number, the heat transfer coefficient is proportional to the complex of $\mu^{0.43} \lambda^{0.57}$. In this case, with increasing particle size, we are faced with two competing tendencies, namely, the viscosity decreases while the thermal conductivity increases. Therefore the dependence of the heat transfer coefficient on the particle size has a maximum. In this particular case it falls on the particle size of $25 \mathrm{~nm}$. This non-monotonic behavior of heat transfer coefficient is probably the main reason for such wide variations and inconsistency in the experimental data on turbulent heat transfer of nanofluids, found in the literature, because, as is obvious, the heat transfer coefficient depends not only on particles concentration but also, in a complex way, on particles size, as well as criterion which is taken for comparative analysis. 


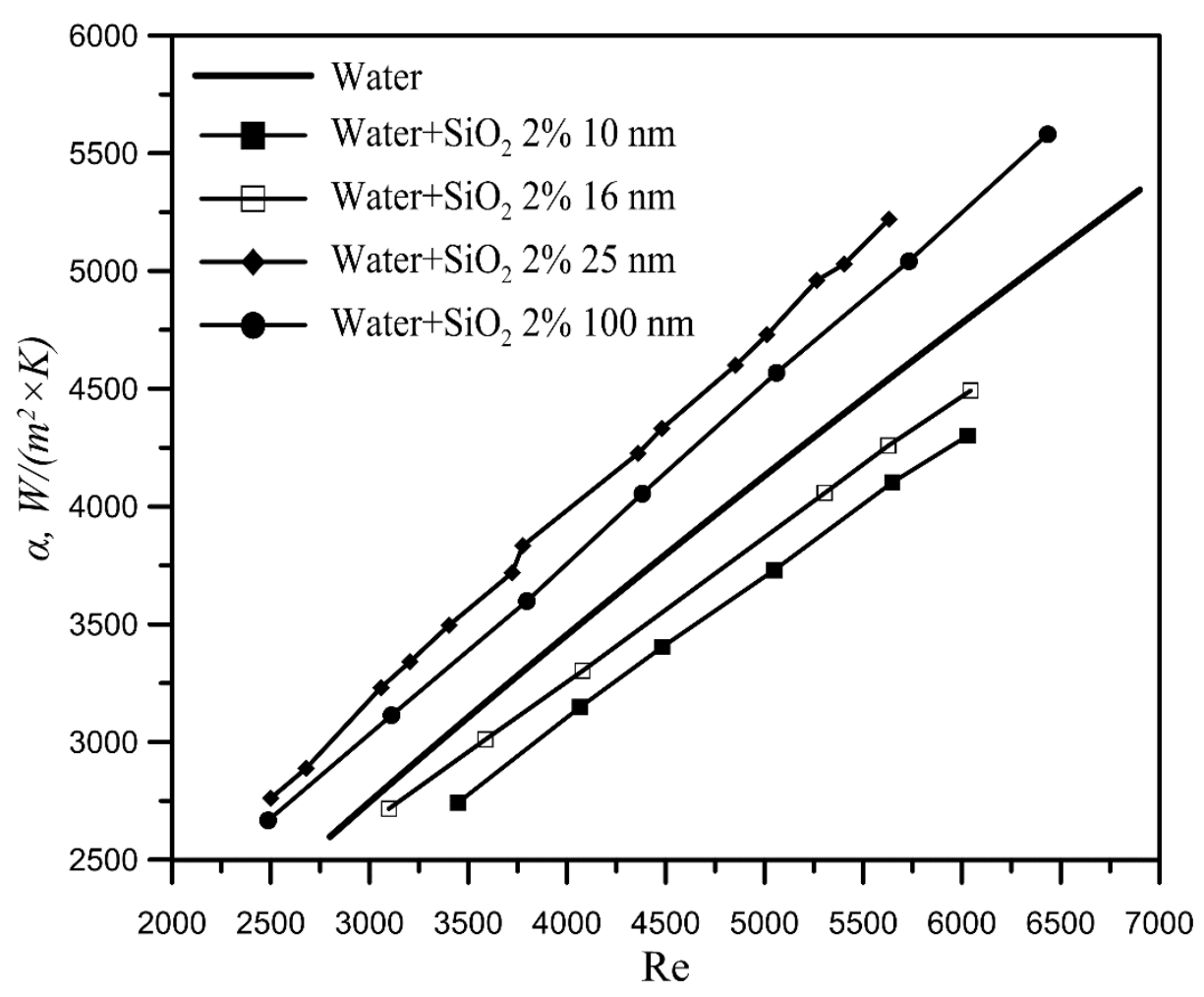

Fig. 12. Heat transfer coefficient versus Reynolds number for various $\mathrm{SiO}_{2}$ nanoparticles sizes at a bulk concentration of $2 \%$.

Thus, it was revealed that at a fixed flow rate of a nanofluid, the heat transfer coefficient increases with increase in nanoparticles size, and has a certain maximum at a fixed Reynolds number.

The effect of nanoparticles size on the properties of nanofluids is also apparent in the pressure drop performance. The data on pressure drop for two sizes of $\mathrm{SiO}_{2}$ particles and the bulk concentration of $1 \%$ are shown in Fig.13. As is obvious, with increasing size of nanoparticles the pressure drop decreases due to lower viscosity. A similar trend is observed in the analysis of the pressure drop at a fixed fluid flow rate. 


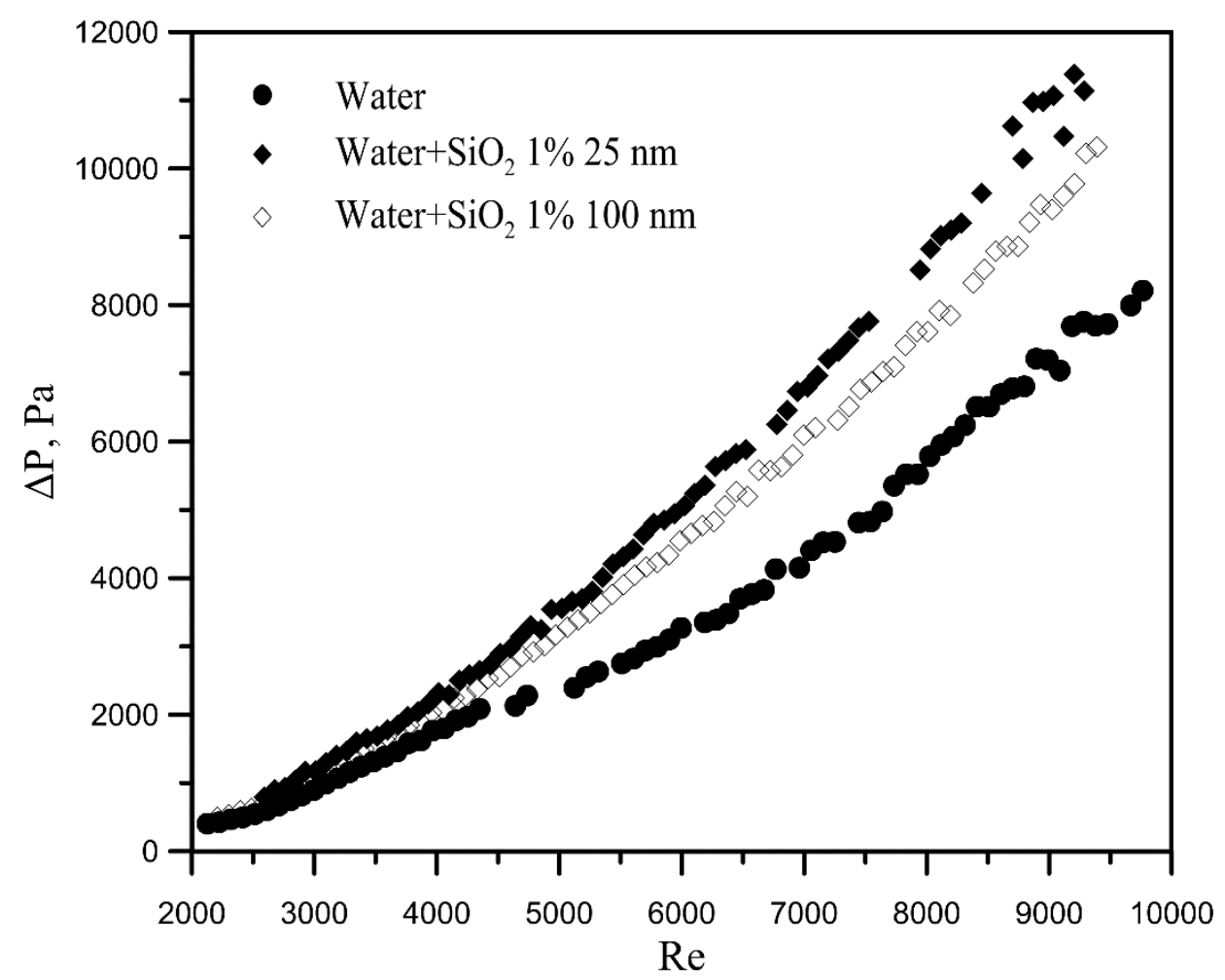

Fig. 13. Pressure drop versus Reynolds number for various $\mathrm{SiO}_{2}$ nanoparticles sizes at a bulk concentration of $1 \%$.

\subsection{The effect of nanoparticles material}

In addition, we have carried out an investigation on the effect of nanoparticles material properties on the heat transfer coefficient and pressure drop in the flowing fluid. Figures 14-15 show the measured data on the heat transfer coefficient for a $2 \%$ concentration of the nanoparticles of silicon and aluminum oxides with a particle size of $100 \mathrm{~nm}$. As is obvious, the heat transfer coefficient for nanofluids containing particles of aluminum oxide is significantly higher than that for nanofluids containing silicon oxide nanoparticles at other conditions being equal. This trend is observed at both fixed flow rate and fixed Reynolds number. The maximum increase in heat transfer coefficient for a $2 \%$ concentration of aluminum oxide particles is about $30 \%$. 


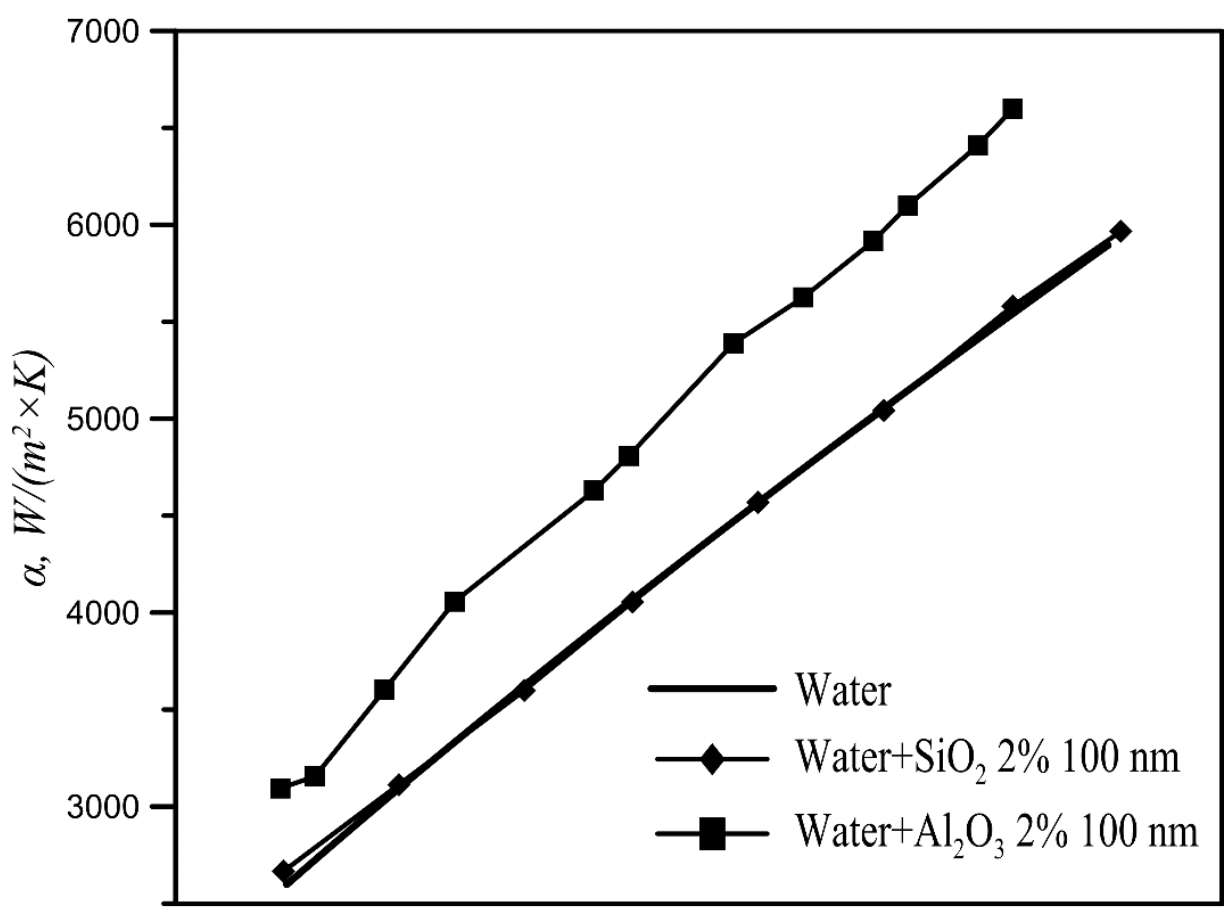

$\mathrm{G}, \mathrm{kg} / \mathrm{s}$

Fig.14. Average heat transfer coefficient versus flow rate for different nanoparticle materials at a bulk concentration of $2 \%$ and particles size of $100 \mathrm{~nm}$.

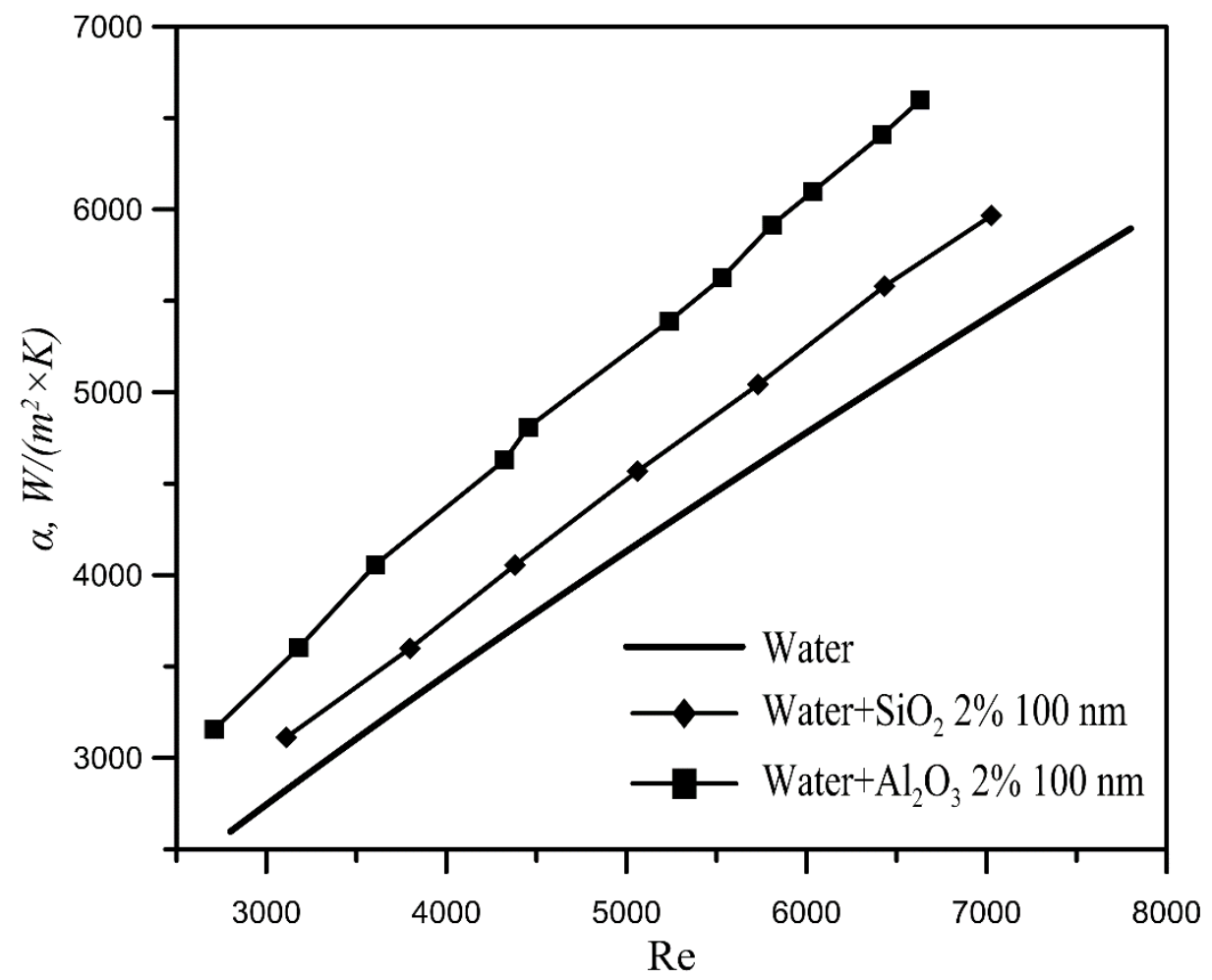

Fig.15. Average heat transfer coefficient versus Reynolds number for different nanoparticle materials at a bulk concentration of $2 \%$ and particles size of $100 \mathrm{~nm}$.

The properties of particles material affect also the pressure drop performance that is shown in Fig.16. As is obvious, the pressure loss for nanofluid containing $\mathrm{Al}_{2} \mathrm{O}_{3}$ nanoparticles is significantly lower. This is because at other conditions being equal nanofluid containing 
aluminum oxide particles has a lower viscosity as compared to nanofluid containing silicon oxide particles (Table 3). This is an interesting finding on its own account, because for classic colloidal solutions there should not be any effect of the nanoparticle material on fluid viscosity. However, the revealed fact is confirmed by molecular dynamics [23] and systematic measurements [24]. The dependence of thermal conductivity coefficient of the nanofluid on the material of the nanoparticles was in principle expected, as Table 3 shows that the thermal conductivity coefficient of nanofluid containing aluminum oxide particles is higher than that of nanofluid containing silicon oxide particles.

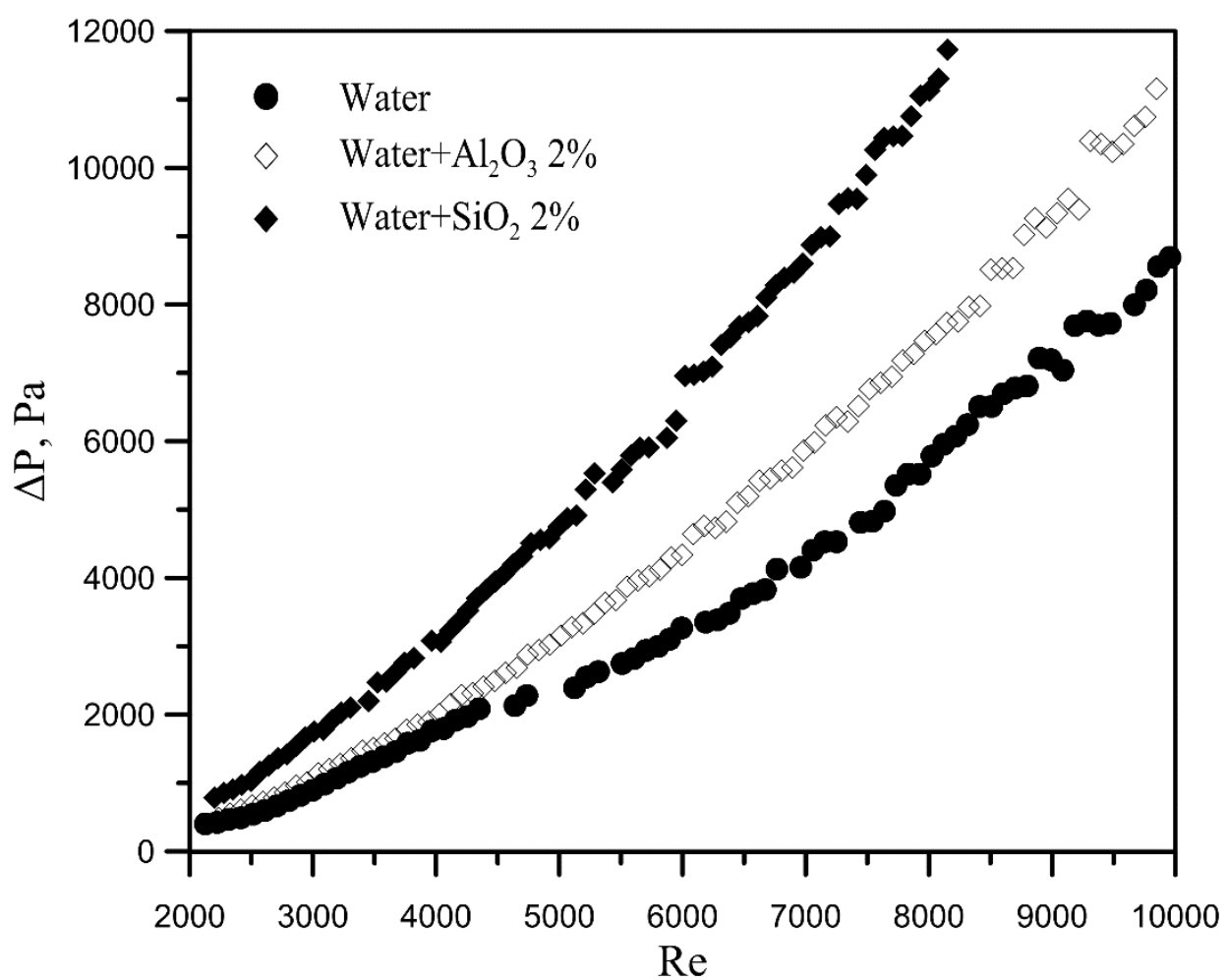

Fig. 16. Pressure drop in nanofluids versus Reynolds number for different nanoparticle materials at particles size of $100 \mathrm{~nm}$.

Table 3. Viscosity and thermal conductivity of different nanofluids at a bulk concentration of $2 \%$ and nanoparticles sizes $100 \mathrm{~nm}$.

\begin{tabular}{|c|c|c|}
\hline & $\mu_{\mathrm{n}} / \mu_{\mathrm{w}}$ & $\lambda_{\mathrm{n}} / \lambda_{\mathrm{w}}$ \\
\hline $\mathrm{SiO}_{2}$ & 1.11 & 1.075 \\
\hline $\mathrm{Al}_{2} \mathrm{O}_{3}$ & 1.083 & 1.13 \\
\hline
\end{tabular}

Thus, the application of nanofluids containing aluminum oxide, at other conditions being equal, is significantly more beneficial than the application of nanofluids containing silicon oxide particles, because in the first case we have a considerably higher heat transfer coefficients and significantly lower pressure losses. This allows controlling the heat transfer process by selecting a desired concentration of particles, their size and material. 


\subsection{The effect of temperature}

Since the viscosity has a significant impact on the heat transfer coefficient and, in turn, the viscosity significantly depends on the temperature, it is obvious that the heat transfer coefficient must also depend on the nanofluid temperature. This is proved by Fig.17, which shows the dependence of heat transfer coefficient on the Reynolds number for three different temperatures at the inlet of the heated test section for nanofluids containing silica particles (100 $\mathrm{nm}$ ) at bulk concentration of $2 \%$. As we see, with increasing fluid temperature, the heat transfer coefficient increases. The increase in the inlet temperature from 15 to $35^{\circ} \mathrm{C}$ leads to increase in heat transfer performance by $60 \%$ at fixed Reynolds number. This is due to the fact that with increasing temperature thermal conductivity increases [27-28], while viscosity, on the contrary, decreases [29]. The most sensitive to changes in temperature, the viscosity of nanofluids. The dependence of viscosity nanofluids on temperature is shown in Table 4. As can be seen with increasing temperature from 15 to 35 degrees viscosity is reduced by about $60 \%$.

Depending from the input temperature is also evident in the behavior of the pressure drop, which is shown in Figure 18. As can be seen, with increasing temperature, the pressure loss is reduced significantly. This is because with increase in temperature decreases the viscosity nanofluids. Therefore, from practical perspective, it is more efficient to apply nanofluids at higher temperatures. Thus it is shown that temperature is another factor having a significant effect on nanofluid turbulent heat transfer.

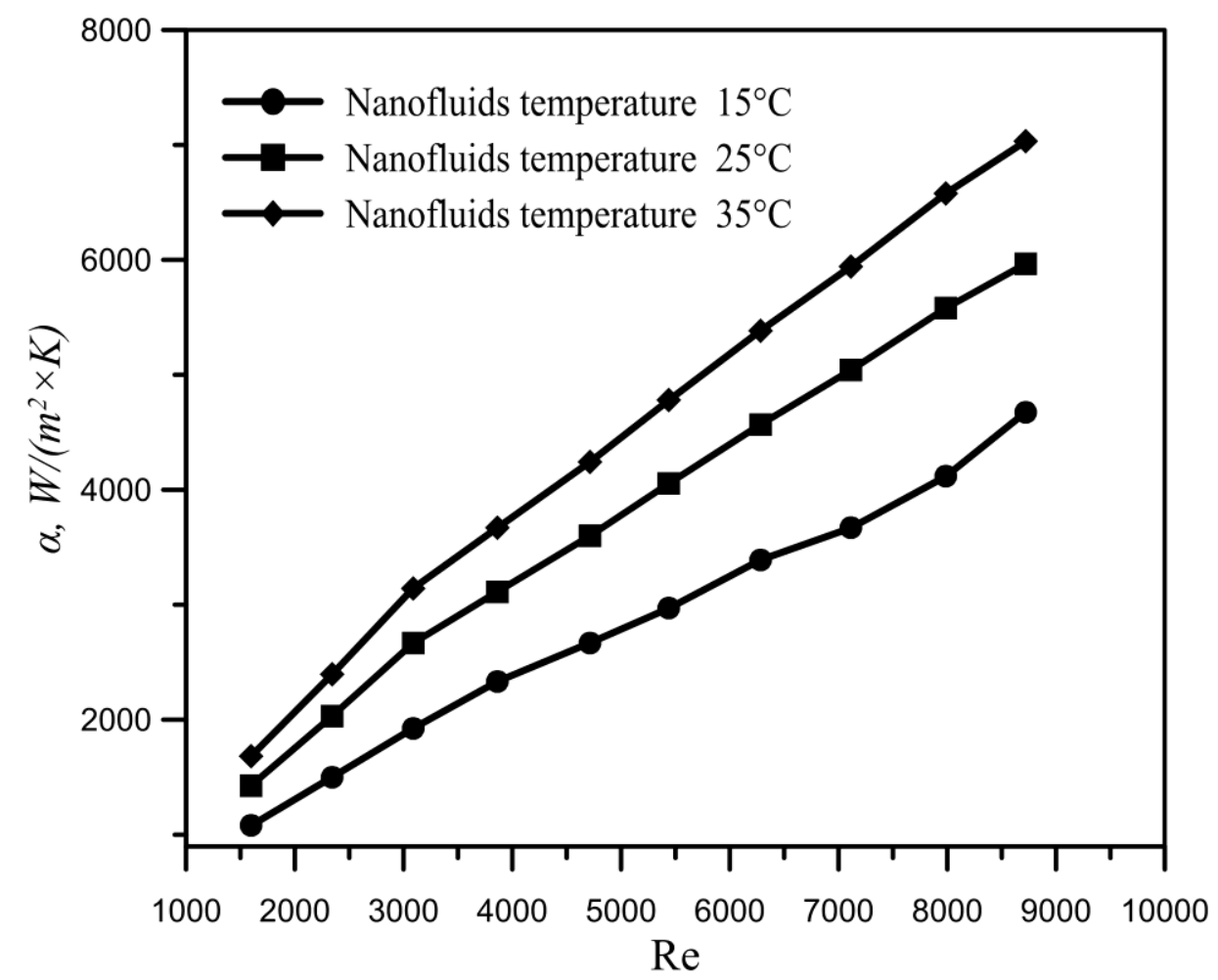

Fig. 17. Heat transfer coefficient versus the Reynolds number at different inlet temperatures of nanofluid containing $\mathrm{SiO}_{2}$ nanoparticles at a bulk concentration of $2 \%$ and particles size of $100 \mathrm{~nm}$. 
Table 4 . The dependence of viscosity nanofluids from temperature.

\begin{tabular}{|c|c|}
\hline $\mathrm{t},{ }^{\circ} \mathrm{C}$ & $\mu_{\mathrm{n}}, \mathrm{cP}$ \\
\hline 15 & 1.282 \\
\hline 25 & 1.002 \\
\hline 35 & 0.807 \\
\hline
\end{tabular}

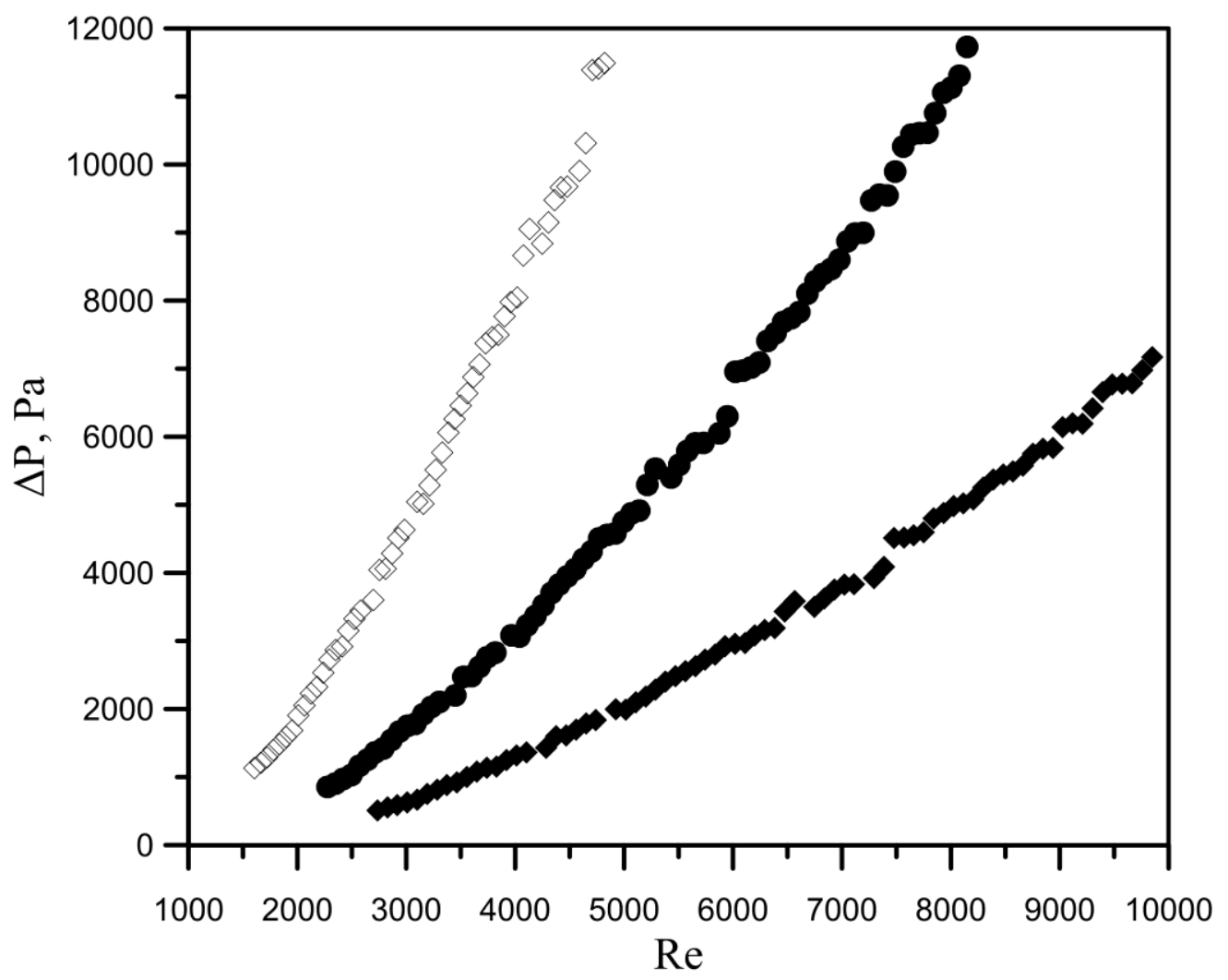

$\diamond \quad$ Nanofluids temperature $15^{\circ} \mathrm{C}$

- Nanofluids temperature $25^{\circ} \mathrm{C}$

- Nanofluids temperature $35^{\circ} \mathrm{C}$

Fig. 18. Pressure drop in nanofluids versus Reynolds number at different inlet temperatures of nanofluid containing $\mathrm{SiO}_{2}$ nanoparticles at a bulk concentration of $2 \%$ and particles size of $100 \mathrm{~nm}$.

\subsection{About the practical effectiveness of nanofluids}

It was shown above that in the case of turbulent flow regime the enhancement of heat transfer coefficient is a non-trivial challenge, which depends on many factors. For example, it depends on the criterion underlying the conducted comparative analysis. Thus, in particular, for a water-based $2 \%$ nanofluid containing silicon oxide nanoparticles, the heat transfer coefficient at a fixed Reynolds number is higher by more than $15 \%$ than that for pure water, whereas at a fixed fluid flow rate it is about $10 \%$ lower than the appropriate value for pure water. 
The question arises, which criterion should be taken to evaluate the practical effectiveness of using the nanofluid as a coolant. It is clear that the use of the Reynolds number as a criterion makes no practical sense. Using a fixed fluid flow rate as a criterion looks more reasonable, because most heat exchange systems are designed for operating at a given constant flow rate. However, we should not forget that adding nanoparticles increases the viscosity of the coolant and this may lower fluid flow rate for some types of pumps. Therefore, the fluid flow rate cannot be taken as an absolute criterion. In our opinion, the most correct and relevant criterion in this case would be the cost for pumping the coolant though the loop. If application of nanofluid increases the heat transfer coefficient as compared to that in pure fluid at the same pumping cost, than such nanofluid can be considered effective. This fact is illustrated by Fig.19, which shows the correlation between heat transfer coefficient and pressure drop in the channel for water and nanofluids containing aluminum oxide and silicon oxide particles. As is obvious, the nanofluid containing silicon oxide particles cannot be considered an effective coolant as compared to pure water because at the fixed pumping cost its heat transfer performance is lower than that for pure water. At the same time, nanofluid containing aluminum oxide nanoparticles is about $15 \%$ more efficient as a coolant than the pure water.

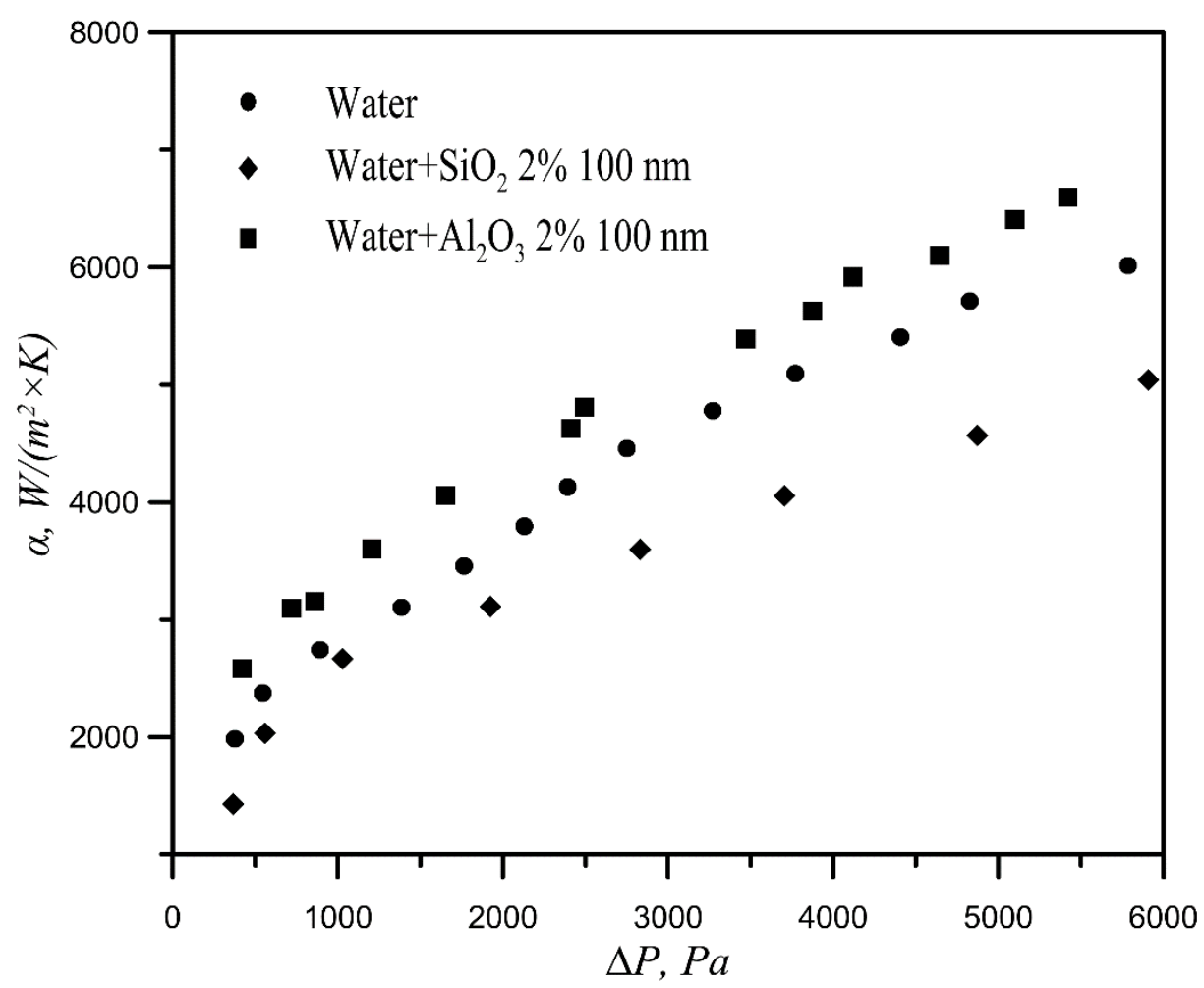

Fig.19. Heat transfer coefficient versus pressure drop at a bulk concentration of $2 \%$ and particles size of $100 \mathrm{~nm}$.

Another criterion that is often used in studies on enhancement of heat transfer is a thermalhydraulic efficiency. This value is according to the Reynolds analogy is defined as 
$\left(N u_{n} / N u_{w}\right) /\left(\xi_{n} / \xi_{w}\right)$. Here, $N u$ - Nusselt number, $\xi$ is the friction factor, index $n$ refers to nanofluids, index $w$ refers to water. The dependence of thermal- hydraulic efficiency from Reynolds number is shown on Fig 20. It can be seen that the thermal-hydraulic efficiency is weakly dependent on the Reynolds number. The efficiency of nanofluids with silica nanoparticles approximately $25 \%$ below of water, and efficiency of nanofluids with aluminum oxide nanoparticles about $8 \%$ above the water.

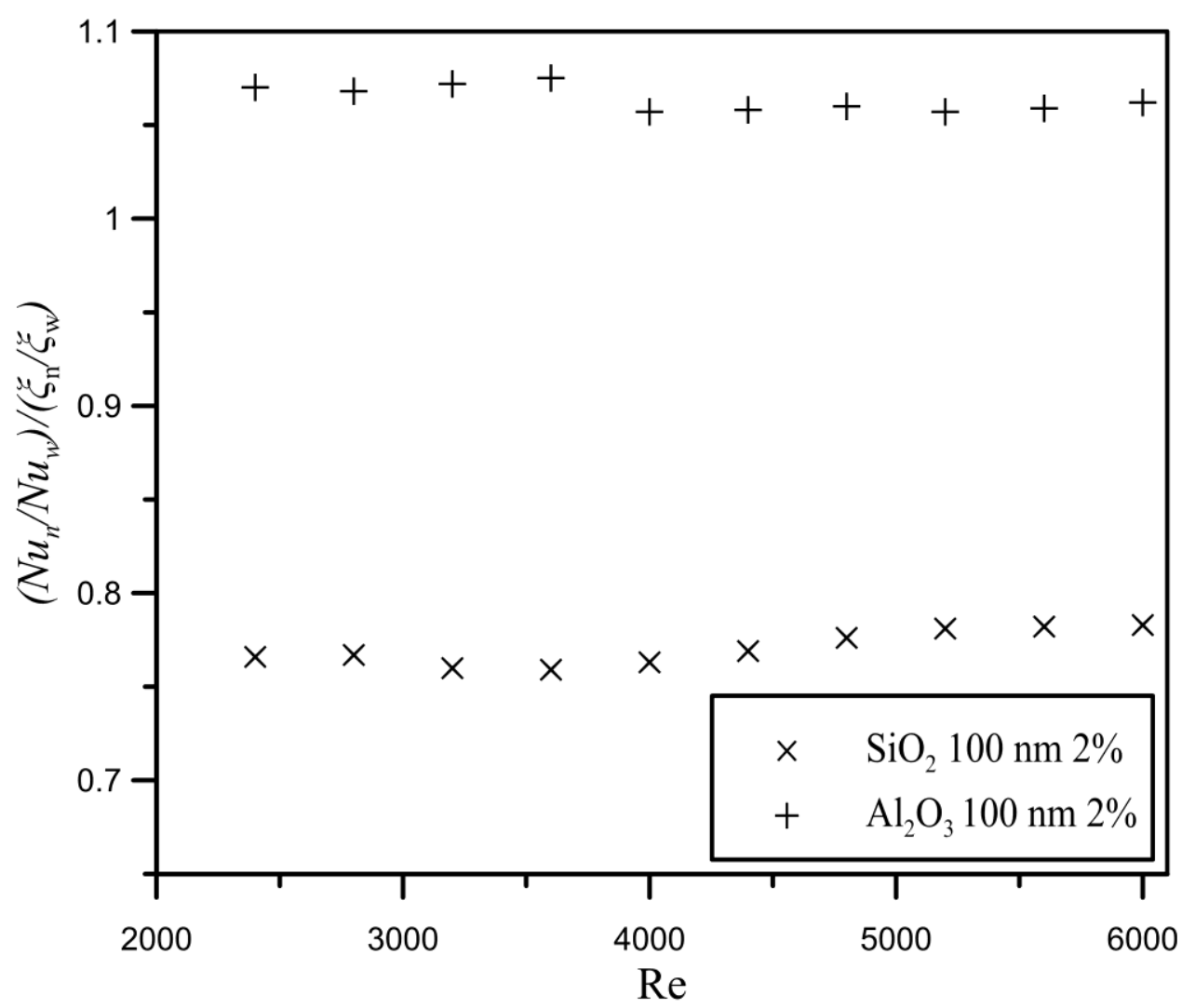

Fig.20. The thermal- hydraulic efficiency versus Reynolds number at a bulk concentration of $2 \%$ and particles size of $100 \mathrm{~nm}$.

\section{CONCLUSION}

An experimental study of turbulent heat transfer of nanofluids has been carried out in a cylindrical channel under constant wall heat flux. The Reynolds number ranged from 3000 to 8000. Powders of aluminum and silicon oxide were used when preparing distilled water-based nanofluids. The nanoparticles diameter ranged from 10 to $100 \mathrm{~nm}$. Bulk concentration of nanoparticles was varied within the range from 0 to 2 volume percent. The average and local values of heat transfer coefficients at the channel walls as well as the pressure drop at the inlet and outlet of the channel were measured in conducted experiments. It was shown that adding 
nanoparticles to the coolant significantly influences the heat transfer coefficient in the turbulent flow regime.

- It is shown that with increasing nanoparticles concentration, the local and average heat transfer coefficients at a fixed Reynolds number increase. Decrease in heat transfer coefficient with increasing particles concentration may take place at a fixed flow rate.

- It is revealed that, the heat transfer coefficient of the nanofluid in turbulent regime increases with increasing nanoparticles size at a fixed flow rate, while has a certain maximum at a fixed Reynolds number.

- The effect of nanoparticles material on the heat transfer coefficient and pressure loss has been also demonstrated.

- It is found that the inlet temperature is another factor having a significant effect on turbulent heat transfer performance of nanofluids. From a practical viewpoint, it is advantageous to ensure highest possible inlet temperature.

Thus, it was shown that heat transfer enhancement due to the use of nanofluids in the turbulent flow regime is a non-trivial problem. Beneficial effect in terms of the heat transfer enhancement depends on the ratio between viscosity and thermal conductivity of nanofluid, and therefore, on the material of particles and their size. When conducting research on nanofluids and analyzing obtained experimental data it is necessary to consider and control many factors and parameters. This apparently explains such a wide variations and inconsistency of experimental data on turbulent heat transfer presented by various authors.

\section{Acknowledgements}

This paper in part of experimental investigation is supported by the Russian Science Foundation (Contract No. 14-19-00312). The theoretical investigation is supported by the Ministry of Education and Science of the Russian Federation Government contract with Siberian Federal University (No. 3100). 


\section{REFERENCES}

1. Ahuja A.S., Augmentation of Heat Transport in Laminar Flow of Polystyrene Suspensions. II. Analysis of the Data, J. Appl. Phys., 1975, V. 46. p. 224.

2. Das S.K., Choi S.U.S. and Patel H. Heat Transfer in Nanofluids. A Review, Heat Transfer Engineering, 2006, V.20, 10, p. 3.

3. Das S.K., Choi S.U.S., and Yu W. and Pradeep T., Nanofluids Science and Technology, New Jersey, Wiley-Interscience, 2007, p. 397.

4. Wang X.-Q. and Mujumbar A.S. Heat Transfer Characteristics of Nanofluids: a Review, Int. J. Thermal Science, 2007. V.46. p. 1.

5. Yu W., France D.M., Choi S.U.S. and Routbort J.L. Review and Assessment of Nanofluid Technology for Transportation and other Applications, Argonne National Laboratory, ANL/ESD/07-9, 2007. p. 78.

6. Terekhov V.I., Kalinina S.V., and Lemanov V.V., Heat Transfer Mechanism in Nanofluids:

State of the Art. Part 2. Convective Heat Transfer, Thermophysics and Aeromechanics, 2010, 2. p. 173.

7. Minakov A.V., Lobasov A.S., Guzei D.V., Pryazhnikov M.I., and Rudyak V.Ya. The Experimental and Theoretical Study of Laminar Forced Convection of Nanofluids in the Round Channel, Applied Thermal Engineering, 2015, №88, pp.140-148.

8. Minakov A.V., Rudyak V.Ya., Guzei D.V., Lobasov A.S. Measurement of the heat transfer coefficient of a nanofluid based on water and copper oxide particles in a cylindrical channel. High Temperature. 2015, Vol. 53, Issue 2, pp. 246-253.

9. Guzei D.V., Minakov A.V., Rudyak V.Ya. Investigation of Heat Transfer of Nanofluids in Turbulent Flow in a Cylindrical Channel. Fluid Dynamics, 2016, Vol. 51, No. 2, pp. 189-199.

10. Pak B.C., and Cho Y.I., Hydrodynamic and Heat Transfer Study of Dispersed Fluids with Submicron Metallic Oxide Particles, Exp. Heat Transfer, 1998, 11, p. 151.

11. Li Qiang, Xuan Yimin, Convective Heat Transfer and Flow Characteristics of Cu-Water Nanofluid, Sci. China. E. 45, 2002, p.408-416.

12. He Y., Jin Y., Chen H., Ding Y., Cang D., and Lu H., Heat Transfer and Flow Behavior of Aqueous Suspensions of $\mathrm{TiO}_{2}$ Nanoparticles (Nanofluids) Flowing Upward through a Vertical Pipe, Int. J. Heat Mass Transfer, 50, 2007, p. 2272.

13. Duangthongsuk W., and Wongwises S., An Experimental Study on the Heat Transfer Performance and Pressure Drop of $\mathrm{TiO}_{2}$-Water Nanofluids Flowing under a Turbulent Flow Regime, Int. J. Heat Mass Transfer, 2010, Vol. 53, pp. 334-344.

14. Fotukian S.M., and Nasr Esfahany. Experimental Investigation of Turbulent Convective Heat Transfer of $\mathrm{Al}_{2} \mathrm{O}_{3}$ /water Nanofluid inside a Circular Tube. Int. J. Heat and Fluid Flow, 
2010, Vol. 31, pp. 606-612.

15. Fotukian S.M., and Nasr Esfahany, Experimental Study of Turbulent Convective Heat Transfer and Pressure Drop of Dilute CuO/Water Nanofluid inside a Circular Tube, Int. Communications in Heat and Mass Transfer, 2010, Vol. 37, pp. 214-219.

16. Nguyen C.T., Roy G., Gauthier C., and Galanis N., Heat Transfer Enhancement Using $\mathrm{Al}_{2} \mathrm{O}_{3}$-Water Nanofluid for Electronic Liquid Cooling System, Applied Thermal Engineering, 2007, 28, p. 1501.

17. Meriläinen A., Seppälä A., Saari K., Seitsonen J., Ruokolainen J., Puisto Rostedt N., and Ala-Nissila T., Influence of Particle Size and Shape on Turbulent Heat Transfer Characteristics and Pressure Losses in Water-based Nanofluids. International Journal of Heat and Mass Transfer, 2013, 61, pp. 439-448.

18. Timofeeva E.V., Yu, W., France D.M., Singh D. and Routbort J.L., Base Fluid and Temperature Effects on the Heat Transfer Characteristics of $\mathrm{SiC}$ in Ethylene glycol/ $\mathrm{H}_{2} \mathrm{O}$ and $\mathrm{H}_{2} \mathrm{O}$ Nanofluids, Journal of Applied Physics, 2011, 109.

19. Tsvetkov F.F., and Grigoriev B.A., Heat and Mass Transfer, Moscow, Moscow Power Engineering Institute, 2005.

20. Minakov A.V., Rudyak V. Ya., Guzei D. V., Pryazhnikov M. I., Lobasov A. S. Measurement of the thermal-conductivity coefficient of nanofluids by the hot-wire method. Journal of Engineering Physics and Thermophysics, 2015, Vol. 88, No. 1, pp. 149-162.

21. Einstein A. A new determination of the molecular dimensions // Ann. Phys., Vol. 19, Pp. 289-306, 1906.

22. Maxwell J.C. A Treatise on Electricity and Magnetism, 2nd ed. - Oxford: Clarendon Press. - 1881, 1, 435.

23. Rudyak V.Ya., Belkin A.A. Modeling transport coefficients of nanofluids. Nanosystems: Phys. Chem. Math., 2010, Vol. 1, № 1, pp. 156-177.

24. Rudyak V.Ya., Minakov A.V., Smetanina M.S., Pryazhnikov M.I. Experimental data viscosity nanofluids water and ethylene glycol-based of the size and material particles. Reports of the Academy of Sciences Vol. 467, № 3, pp. 1-3.

25. Ali F.M., Yunus W.M.M. and Talib Z.A. Study of the Effect of Particles Size and Volume Fraction Concentration on the Thermal Conductivity and Thermal Diffusivity of $\mathrm{Al}_{2} \mathrm{O}_{3}$ Nanofluids. International Journal of Physical Sciences, 2013, Vol. 8(28), pp. 1442-1457.

26. Beck M.P., Yuan Y., Warrier P., and Teja A.S. The Effect of Particle Size on the Thermal Conductivity of Alumina Nanofluids. J. of Nanoparticle Research, 2009, 11, pp.1129-1136.

27. Sayantan Mukherjee, Purna Ch. Mishra, S. K. S. Parashar, Paritosh Chaudhuri. Role of temperature on thermal conductivity of nanofluids: a brief literature review. Short 
Communication Heat and Mass Transfer. 2016. P. 1-11.

28. Duangthongsuk W, Wongwises S. Measurement of temperature-dependent thermal conductivity and viscosity of TiO2- water nanofluids. Exp Thermal Fluid Sci. 2009. 33:706-714. 29. V. Ya Rudyak, S. V. Dimov, and V. V. Kuznetsov. On the Dependence of the Viscosity Coefficient of Nanofluids on Particle Size and Temperature. Technical Physics Letters, 2013, Vol. 39, No. 9, pp. 779-782. 